\title{
A quantitative flood risk analysis methodology for urban areas with integration of social research data
}

\author{
I. Escuder-Bueno ${ }^{1}$, J. T. Castillo-Rodríguez ${ }^{1}$, S. Zechner ${ }^{2}$, C. Jöbstt ${ }^{2}$, S. Perales-Momparler ${ }^{3}$, and G. Petaccia ${ }^{4}$ \\ ${ }^{1}$ Universitat Politècnica de València, Research Institute of Water and Environmental Engineering, Valencia, Spain \\ ${ }^{2}$ Graz University of Technology, Institute of Hydraulic Engineering and Water Resources Management, Graz, Austria \\ ${ }^{3}$ PMEnginyeria, Valencia, Spain \\ ${ }^{4}$ University of Pavia, Department of Civil Engineering and Architecture, Pavia, Italy
}

Correspondence to: J. T. Castillo-Rodríguez (jecasrod@upvnet.upv.es)

Received: 12 December 2011 - Revised: 24 July 2012 - Accepted: 30 July 2012 - Published: 12 September 2012

\begin{abstract}
Risk analysis has become a top priority for authorities and stakeholders in many European countries, with the aim of reducing flooding risk, considering the population's needs and improving risk awareness. Within this context, two methodological pieces have been developed in the period 2009-2011 within the SUFRI project (Sustainable Strategies of Urban Flood Risk Management with non-structural measures to cope with the residual risk, 2nd ERA-Net CRUE Funding Initiative). First, the "SUFRI Methodology for pluvial and river flooding risk assessment in urban areas to inform decision-making" provides a comprehensive and quantitative tool for flood risk analysis. Second, the "Methodology for investigation of risk awareness of the population concerned" presents the basis to estimate current risk from a social perspective and identify tendencies in the way floods are understood by citizens. Outcomes of both methods are integrated in this paper with the aim of informing decision making on non-structural protection measures. The results of two case studies are shown to illustrate practical applications of this developed approach. The main advantage of applying the methodology herein presented consists in providing a quantitative estimation of flooding risk before and after investing in non-structural risk mitigation measures. It can be of great interest for decision makers as it provides rational and solid information.
\end{abstract}

\section{Introduction}

In the recent past, flooding from a wide range of sources (river, pluvial, coastal or maritime flood events) seemed to happen more frequently with snowballing effects for the landscape and society. In fact, one-third of the annual natural disasters and economic losses and more than half of all victims are flood related (Douben, 2006). In the period 19752001, floods due to drainage problems, flash floods and river floods accounted for $9 \%$ of all deaths from natural disasters, claiming about 175000 fatalities worldwide (Jonkman, 2003). Furthermore, present requirements of residential and industrial areas have resulted in new urban developments in flood prone areas, increasing risk to people and assets.

As a result, social demand for higher levels of safety has become a major challenge for the governments of European countries. Though safety is typically linked in engineering to "existing margin to structural collapse", when it comes to flooding, methodologies to support decision making should be based on a much broader concept such as risk (societal, economic, etc.). This allows us to analyze the combined effect of hazard and vulnerability so that the impact on risk of a wide range of options - from an increase of structural safety to a series of non-structural actions such as flood forecasting, warning, emergency management, etc. - can be accounted. The SUFRI project (Sustainable Strategies of Urban Flood Risk Management with non-structural measures to cope with residual risk, 2nd ERA-Net CRUE Funding Initiative) focused on non-structural measures and their impact in risk reduction, including how they enhance social resilience. 
However, flood risk cannot be completely eliminated and there will always remain a residual risk.

Additionally, under the EU Floods Directive 2007/60/EC (EC, 2007), a broad basis of knowledge and tools, as well as improved strategies for flood risk management, are being developed. In particular, a key aspect of effective flood risk management is the evaluation of the current situation and the effect of implementing new measures.

In more detail, the need for strategies to improve flood risk management requires the development of advanced warning systems, vulnerability analysis and risk communication to optimize emergency management (Baana and Klijna, 2004; Roos, 2006; Samuels et al., 2006; Sayers et al., 2002; Simonovic, 1999; Graham, 1999).

This submission presents a comprehensive methodology for urban flood risk analysis integrating social research survey data to support the study of non-structural measures. The aim of this approach is to combine both technical and social aspects to inform the decision-making process, showing the impacts of such measures on economic and societal risk.

Two case studies, one focused on an application for a municipality affected by pluvial flooding (Benaguasil, Spain) and a second focused on an urban area (Lodi, Italy) affected by river flooding, are also included to show how the methodology can be applied and used.

\section{Overall framework}

This section describes the integration of social research data into quantitative flood risk analysis in urban areas with the aim of prioritizing actions for flood risk reduction.

First, Sect. 2.1 summarizes a methodology for pluvial and river flooding risk analysis in urban areas to inform decision making, developed within the SUFRI project and described in detail in its final report (Escuder-Bueno et al., 2011a). Second, Sect. 2.2 summarizes the conceptual basis and a short description of the public opinion poll proposed in the project (Zechner et al., 2011) for estimating public risk awareness and perception of non-structural measures. Next, Sect. 2.3 presents the original approach for the integration of social research data into quantitative flood risk analysis and how the results of opinion polls can be used to incorporate information into the analysis and evaluate the effect of non-structural measures on flood risk reduction.

\subsection{Quantitative flood risk assessment in urban areas}

The methodology herein presented aims at combining the use of risk models and $F-N$ plus $F-D$ curves to provide a complete and quantitative tool for flood risk estimation (EscuderBueno et al., 2011b).

$F-N$ curves are a graphical representation of the probability of events causing a specified level of harm to a specific population (IEC 31010). $F-N$ curves show the cumulative frequency $(F)$ at which $N$ or more members of the population will be affected. Similarly, $F-D$ curves show the cumulative frequency $(F)$ for each level of potential economic damages $(D)$.

This methodology can be applied for analysing any source of flood hazard, but it has been developed in detail for pluvial and river flooding. In addition, the methodology could be applied not only to urban areas but also to flood risk analysis at different scale levels (e.g. a number of municipalities within the flooded area of a river course, regional level, etc.).

\subsubsection{Basis}

The $F-N$ and $F-D$ curves are quantitative and comprehensive tools for estimating flood risk in a certain area. The $F-N$ curve presents the cumulative annual exceedance probability of the expected estimated level of potential fatalities and the area under the curve corresponds to total societal risk. The $F-D$ curve illustrates the estimated level of economic damages and the area under the curve represents economic risk.

These curves are a useful way of presenting risk information that can be used by managers and system designers to help decision making about risk (IEC 31010), and they are appropriate for comparison of risks from different situations when sufficient data is available, such as the comparison between the situation with and without a number of non-structural measures.

At this point, a short clarification on the definition of nonstructural measure is given. In contrast to structural measures, the term "non-structural measure" is not clearly specified and often used ambiguously. The project FLOOD-ERA (1st CRUE ERA-Net Funding Initiative) analyzed and compared existing concepts and proposed a new systematization of structural and non-structural measures (CRUE, 2009; Schanze et al., 2008). Following this systematization, structural measures are considered as any intervention in the flood risk system based on (structural) works of hydraulic engineering. As a result, non-structural measures are all other interventions, mainly focused on acting on potential consequences.

Figure 1 shows the $F-D$ curve for a hypothetic urban area as an example (Escuder-Bueno et al., 2010). This figure depicts the effect of structural and non-structural measures on flooding risk, using typical (but fictitious) values in both axes (annual exceedance probability and estimated economic damages) that have to be properly estimated for each particular case.

Three different curves are presented in Fig. 1: first, the situation without any protection measures (dashed line); second, the situation of the study area with structural measures such as drainage systems, dikes, small and large dams (solid line); and, finally, the situation with both structural and nonstructural measures (dotted line).

Depending on what kind of structural measure is considered, the $F-N$ or $F-D$ curve will capture a decrease in the 


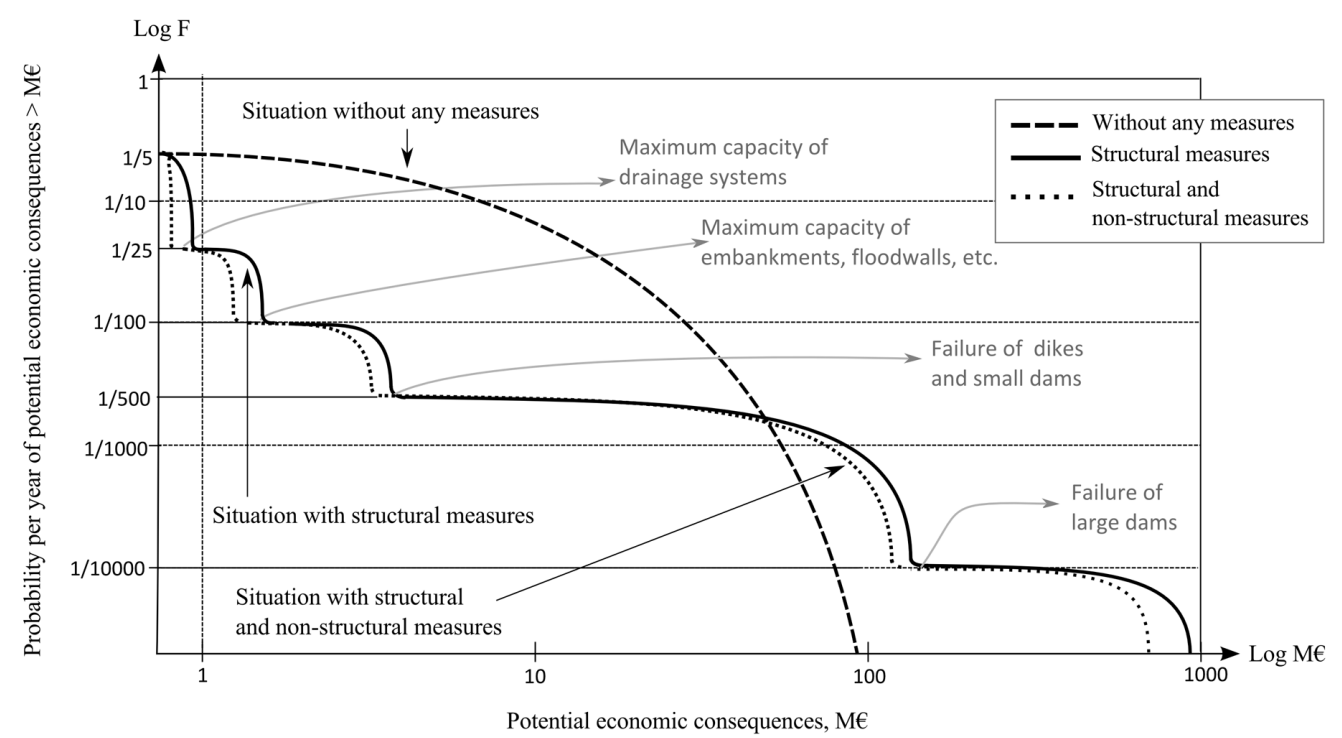

Fig. 1. Effect of structural and non-structural measures on the $F-D$ curve (Escuder-Bueno et al., 2010).

annual probability of exceedance (e.g. drainage systems), an increase in the estimated consequences (e.g. breakage of a large dam or levee), or any other change in the frequency or magnitude of the alternative being analyzed. Moreover, the $F-N$ and $F-D$ curves capture the impact of non-structural measures on flood consequence reduction. Consequently, these curves are the basis of the presented methodology for quantitative flood risk analysis in urban areas.

Based on the definition of the $F-N$ or $F-D$ curves as the representation of the annual cumulative exceedance probability of a certain level of consequences, both societal and economic risk can be represented in terms of potential fatalities or economic damages, respectively.

On the one hand, societal risk can be obtained by estimating potential fatalities based on guidelines found in the literature (e.g. Graham, 1999; DHS, 2011a, b; Penning-Rowsell et al., 2005). In general, these guidelines focus on estimating the population at risk, the population exposed to the flood and fatality rates that are coupled with flooding simulations (peak discharges, arrival wave times, water depths, velocities, flooded areas, etc.).

On the other hand, economic risk can be obtained by estimating potential economic damages from flooded areas, land-use values and depth-damage curves. These curves provide an expected percentage of damages in households, buildings, vehicles, etc. (e.g. COPUT, 2002; Dawson, 2003; Scawthorn et al., 2006) for a certain flood depth. Consequently, extent of flooded areas, reference costs for affected assets and depth-damage curves are used to estimate direct costs. Estimation of indirect costs (e.g. Messner et al., 2007) requires detailed information of the urban area (e.g. loss of production, traffic disruption, costs of emergency services, etc.). In general, indirect costs may be estimated as a percentage of direct costs based on local characteristics. A more

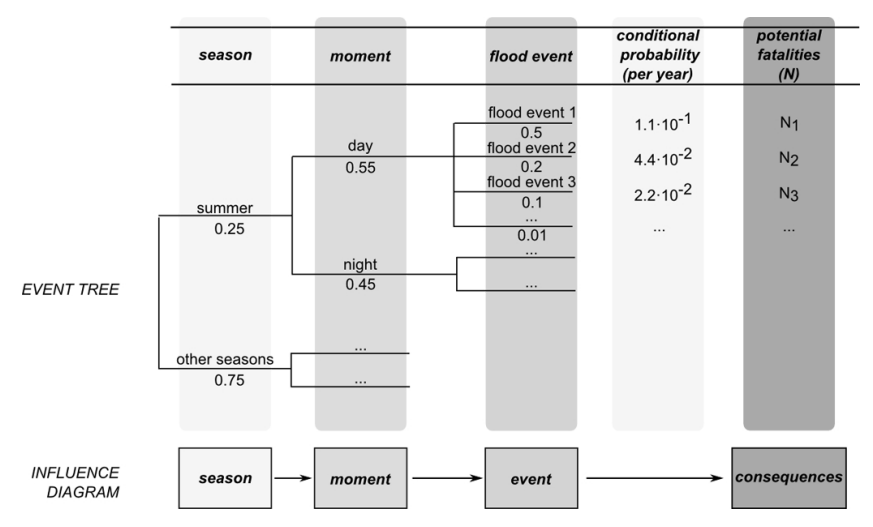

Fig. 2. Generic event tree and compact representation using an influence diagram.

detailed analysis may be necessary, for example, in case of flood events of long duration, existence of hazardous industries or impact in critical infrastructures as defined in EU Directive 2008/114/EC (EC, 2008). With the aim of performing such combinations, this methodology proposes one of the most applicable ways of implementing risk calculations: the use of event trees to compute flood event probabilities and consequences (Serrano-Lombillo et al., 2009).

An event tree is an exhaustive representation of all the events and possibilities that can lead to, for example, the failure of a flood defence infrastructure. It is commonly used as a tool for carrying out the calculation of a failure probability or the risk associated to it (Serrano-Lombillo et al., 2009). Each branch of the event tree comprises a possible flood event with related conditional probabilities and potential consequences (Fig. 2 shows a simplified example). 
Within the event tree framework, risk models are proposed to perform the analysis by using a simplified scheme or influence diagram that includes all necessary information to develop the event tree and characterize flood risk.

Consequently, influence diagrams are a compact conceptual representation of the logic of a system. In its most generic form, an influence diagram can be any graphic representation which includes the relationships between possible events (loads), state and response of the system, and consequences. An influence diagram offers a visual representation of the risk model, in which each variable is represented by a node and each relationship by an arc.

In particular, the iPresas software (Serrano-Lombillo et al., 2009) has been used to carry out risk calculations. Influence diagrams are built instead of directly using event trees, providing a clear, concise and visual workflow. The software algorithm transforms influence diagrams into event trees and it can be used for any problem that may arise in the field of risk analysis.

The methodology here summarized (presented in EscuderBueno et al., 2011b) is flexible enough for performing different risk models as required in any urban area.

\subsubsection{Phases to apply the methodology}

\section{Phase I - Scope of the case study}

This phase consists of properly defining the scope of the study and the required level of detail, with focus on data and time requirements to perform the risk model and calculations.

\section{Phase II - Review of available data}

The level of uncertainty in risk estimations will depend on available information (data collection, site visits, etc.). The analysis may include a wide range of studies such as seasonal and daily variations in population, value of assets, land-use distribution, flood prone areas, hydraulic and hydrological studies.

\section{Phase III - Study of the system situation: definition of the Base Case}

Before analysing non-structural measures, it is necessary to study the current situation of the urban area (defined as Base Case). The risk model of the Base Case considers the range of possible flood events due to different load scenarios, including the potential failure of all existent infrastructures (e.g. levees, dikes, dams, drainage system, etc.).

\section{Phase IV - Flood events}

Once the proper range of flood events to be considered in the analysis is established, each of these events, characterized by a certain annual probability of exceedance, will be linked to conditional probabilities and potential consequences through the risk model.

\section{Phase V - Risk model architecture}

The risk model comprises three generic parts or categories of information: loads, system response and consequences. First, "loads" refers to nodes with information on load scenarios (e.g. if a dam is located upstream of the urban area, it includes data on floods, previous water pool levels, gate reliability and flood routing); next, "system response" includes nodes with information on failure and non-failure cases of flood defence systems; and finally, "consequences" includes potential economic damages and fatalities.

\section{Phase VI - Input data for the risk model}

Information from hydrological studies of the catchment area, analyses of system response (failure modes, hydraulic characteristics of the flood, etc.), and estimations of life-loss and economic damages are used as input data to calculate societal and economic risk.

First, life-loss is estimated following different methods for pluvial and river flooding (Escuder-Bueno et al., 2011a), but, in general, the number of potential fatalities is obtained by multiplying population at risk times the fatality rate for each event resulting in flooding. Second, economic losses are assessed by identifying homogenous areas, defining reference costs, and estimating percentages of damage, etc. to calculate direct and indirect costs (e.g. COPUT, 2002).

\section{Phases VII and VIII - Risk calculation and development of $F-N$ curves}

All flood events and potential consequences are implemented into the risk model to provide values of societal and economic risk (Phase VII). Then, series of annual probability of exceedance for each value of consequences (loss of life or economic losses) are obtained to represent $F-N$ and $F-D$ curves (Phase VIII). Thus, societal and economic risk can be calculated and represented.

\section{Phase IX - Risk evaluation}

Societal and economic risk can be potentially evaluated by comparing results with existing tolerability criteria or standards when available.

\section{Phase X - Study of non-structural measures}

Non-structural measures cover a wide spectrum of different actions like, for instance, warning tools, flood proofing and planning instruments (Schanze et al., 2008). In this paper, existing non-structural measures for flood risk reduction are classified into four main groups: 
- Public education (denoted as PE),

- Warning systems and emergency management (denoted as EM),

- Coordination between authorities and emergency services (denoted as $\mathrm{CO}$ ),

- Communication to the public (denoted as CM).

Typically, these measures can have a significant impact on the overall risk by diminishing consequences, both on lives and the economy.

Consequently, the methodology captures the effect of the previously mentioned four groups of non-structural protection measures into existent flood severity understanding and risk awareness of population at risk with the aim of characterizing the expected consequences. Therefore, a review of previous phases is required to estimate new potential consequences and the corresponding $F-N$ or $F-D$ profiles in order to compare the Base Case with the situation after implementing such measures on risk reduction.

\subsubsection{Impact of non-structural measures on potential consequences}

This section summarizes how potential consequences are estimated in pluvial and river flooding, including the impact of non-structural measures on this stage of the flood risk analysis.

\section{Pluvial flooding}

In pluvial flooding, potential consequences in terms of loss of life can be estimated as the combination of population exposed to the flood and fatality rates related to the characteristics of the flood. With that purpose, a classification of five flood severity levels (from S0, where low levels of victims are expected, to $\mathrm{S} 4$, extreme severity) was established, based on a set of data collected from literature review (Gómez and Russo, 2009; Reiter, 2001; Nanía, 2002; Témez, 1991) including theoretical studies and experimental data. After representing all the available data together, five flood severity levels were defined by the combination of different hydraulic parameters such as flood depth, velocity, dragging and sliding parameters (Table 1 and Fig. 3).

Once each flood severity level had been defined based on hydraulic characteristics, fatality rates were obtained based on the method proposed by Penning-Rowsell et al. (2005). This method focuses on the estimation of the total number of people located in flood-prone areas, the proportion of those people who are likely to be exposed to it, and those who may be injured or killed.

With the aim of providing different fatality rates based on the existence of warning systems and their impact on potential loss of life, three different levels of flood warning are

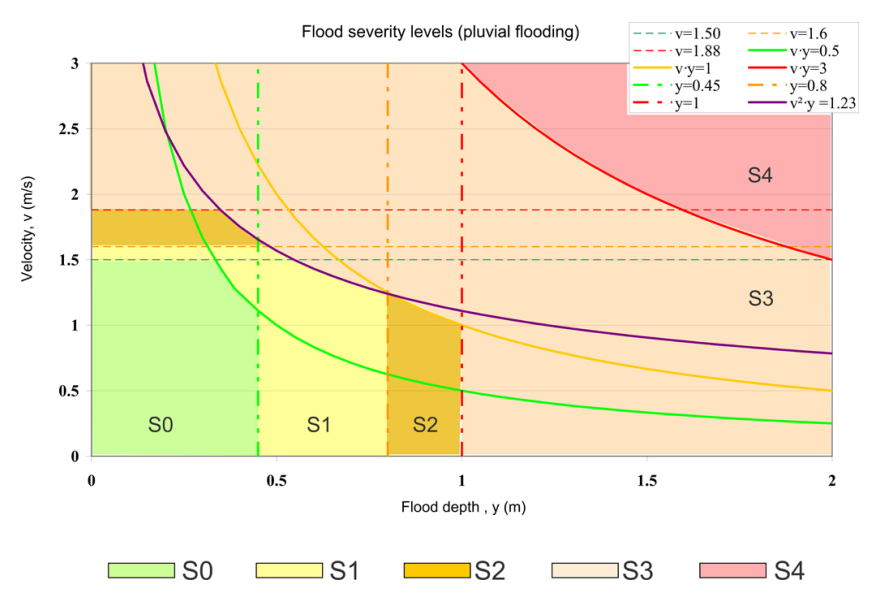

Fig. 3. Flood severity levels for estimating consequences in pluvial flooding (Escuder-Bueno et al., 2011a).

considered. These levels are based on the three factors proposed by Penning-Rowsell et al. (2005) to characterize area vulnerability (flood warning, speed of onset and nature of area). Flood warning is captured by the FW parameter. This factor score ranged from 1 to 3 depending on available warning systems, which are characterized in terms of emergency planning, awareness and preparedness of the affected population, and preparing and issuing flood warnings. Consequently, any urban area can be classified in one of the three categories shown in Table 2 and linked to one of the three values of $\mathrm{FW}$.

Table 2 lists the established categories concerning the existence of flood warning systems: first, urban areas where no warning systems are available; second, areas where warning systems do exist, but their effectiveness cannot be ensured; and finally, areas with verified or advanced warning systems. Consequently, any urban area can be classified in one of these three different situations as shown in Table 2.

For each category $\left(C_{\mathrm{p} 1}\right.$ to $\left.C_{\mathrm{p} 3}\right)$ and flood severity level ( $S 0$ to $S 4$ ), fatality rates are estimated using mean values for building typology, people vulnerability and the so-called area vulnerability factors (except for the FW parameter, Table 2). If other characteristics of the population are considered, fatality rates should be corrected following the guidelines given in Penning-Rowsell et al. (2005). In addition, mean values of water depth and velocity were used for each flood severity level to provide a reference value for each category, $C_{\mathrm{p}}$, and flood severity level, $S$. Consequently, fifteen fatality rates have been proposed as shown in Fig. 4.

\section{River flooding}

Flood hydraulic characteristics (e.g. water depths, velocities, rise-rate, flood areas, etc.) in river flooding differ from pluvial flooding. As a result, different methods should be applied to estimate potential consequences. Ten categories were established (Escuder-Bueno et al., 2011a) to assess potential 
Table 1. Flood severity levels for estimating consequences in pluvial flooding (Escuder-Bueno et al., 2011a).

\begin{tabular}{llrrrr}
\hline Flood severity levels & $(S)$ & $\begin{array}{r}\text { Depth } \\
y(\mathrm{~m})\end{array}$ & $\begin{array}{r}\text { Velocity } \\
v\left(\mathrm{~m} \mathrm{~s}^{-1}\right)\end{array}$ & $\begin{array}{r}\text { Dragging parameter } \\
v y\left(\mathrm{~m}^{2} \mathrm{~s}^{-1}\right)\end{array}$ & $\begin{array}{r}\text { Sliding parameter } \\
v^{2} y\left(\mathrm{~m}^{3} \mathrm{~s}^{-2}\right)\end{array}$ \\
\hline$S 0$ & No victims are expected. People expected to survive. & $<0.45$ & $<1.50$ & $<0.50$ & $<1.23$ \\
$S 1$ & $\begin{array}{l}\text { Low severity } \\
\text { Pedestrians may suffer loss of stability. People in dan- } \\
\text { ger. }\end{array}$ & $<1.80$ & $<1.60$ & $<1.00$ & $<1.23$ \\
$S 2$ & $\begin{array}{l}\text { Medium severity } \\
\text { Significant loss of stability. Cars can lose road holding. }\end{array}$ & $<1.00$ & $<1.88$ & $<1.00$ & $<1.23$ \\
& $\begin{array}{l}\text { Floating. } \\
S 3\end{array}$ & & & \\
$\begin{array}{l}\text { High severity } \\
\text { High risk for people outside. } \\
\text { Low risk for buildings. }\end{array}$ & $>1.00$ & $>1.88$ & $>1.00$ & $>1.23$ \\
$S 4$ & $\begin{array}{l}\text { Extreme severity } \\
\text { Structural damages on buildings. }\end{array}$ & $>1.00$ & $>1.88$ & $>3.00$ & $>1.23$ \\
\hline
\end{tabular}

Table 2. Categories for defining fatality rates in pluvial flooding (Escuder-Bueno et al., 2011a).

\begin{tabular}{llr}
\hline & & FW parameter \\
ID & Category & Penning-Rowsell et al. (2005) \\
\hline$C_{\mathrm{p} 1}$ & No warning systems are available & 3 \\
$C_{\mathrm{p} 2}$ & Warning systems do exist but not used & 2 \\
$C_{\mathrm{p} 3}$ & Verified and advanced warning systems & 1 \\
\hline
\end{tabular}

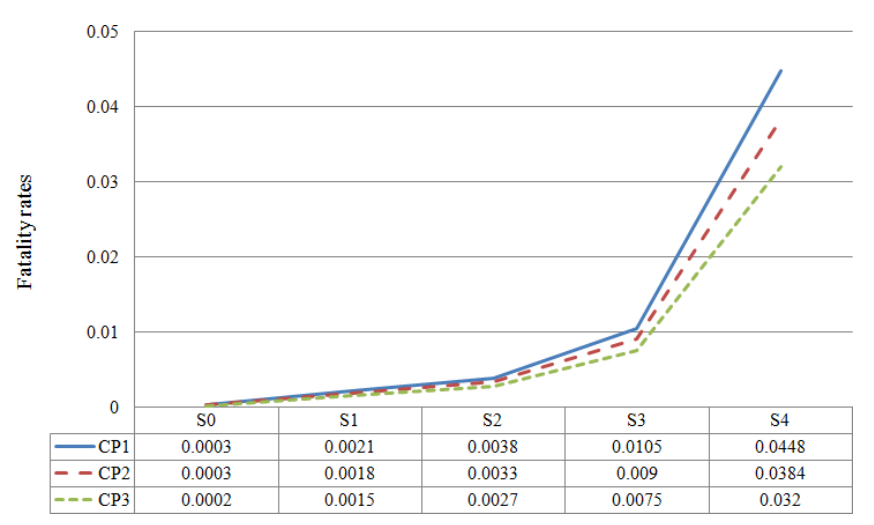

Fig. 4. Fatality rates for pluvial flooding for each category and flood severity level.

loss of life in urban areas in case of river flooding. This classification of ten categories ( $C 1$ to $C 10)$ has been developed depending on the existence of public education on flood risk, warning systems, risk communication, and coordination between emergency agencies and authorities. It defines a certain level of flood severity understanding for each category, linked to fatality rates based on a compilation of historical data and existing reference values on loss of life (Graham, 1999; USBR, 2001). Consequently, different fatality rates are considered for each category ( $C 1$ to $C 10)$ depending on available warning times (from 0 to $24 \mathrm{~h}$ ) and three flood severity levels (Table 3 ). These three severity levels depend on characteristics of river flooding such as the peak discharge in the flooded area, mean annual peak discharge and extent of the flood (Graham, 1999). Thus, once the existing public education, emergency management, communication and coordination systems are evaluated for the urban area, a certain category is used to associate fatality rates with the analyzed flood events. Accordingly, the analysis of a non-structural measure (e.g. implementation of an Emergency Action Plan for Dams) will potentially result in a new category with respect to the Base Case.

\subsection{Social research to investigate population risk awareness}

\subsubsection{Basis}

Different groups are involved in the flood risk management process. Alongside the task forces, the affected population is asked to act in a proper way to reduce possible consequences of flooding. In this context, effective risk communication plays a major role to initiate, support, maintain and keep up the knowledge about flood reducing measures and adequate behaviour. To be able to design an effective communication plan for a crisis, the following factors must be taken into consideration: people's behaviours, as well as their 
Table 3. Fatality rates in case of river flooding (Escuder-Bueno et al., 2011a).

\begin{tabular}{|c|c|c|c|c|c|}
\hline \multirow[t]{2}{*}{ ID } & \multirow{2}{*}{$\begin{array}{l}\text { Category for the case study } \\
(C)\end{array}$} & \multirow[t]{2}{*}{$\begin{array}{r}\text { Warning time } \\
\text { TW (h) }\end{array}$} & \multicolumn{3}{|c|}{$\begin{array}{l}\text { Flood severity } \\
\qquad(\mathrm{Sv})\end{array}$} \\
\hline & & & High (3) & Medium (2) & Low (1) \\
\hline$C 1$ & $\begin{array}{l}\text { - There is no public education on flood risk terms. } \\
\text { - No warning systems, no EAP (Emergency Action Plan). } \\
\text { - There is no coordination between emergency agencies and } \\
\text { authorities. } \\
\text { - No communication mechanisms to the public. }\end{array}$ & $\begin{array}{r}0 \\
0.25 \\
0.625 \\
1 \\
1.5 \\
24\end{array}$ & $\begin{array}{r}0.9 \\
0.9 \\
0.7 \\
- \\
- \\
-\end{array}$ & $\begin{array}{r}0.3 \\
0.3 \\
0.08 \\
0.06 \\
0.0002 \\
0.0002\end{array}$ & $\begin{array}{r}0.02 \\
0.02 \\
0.015 \\
0.0006 \\
0.0002 \\
0.0001\end{array}$ \\
\hline$C 2$ & $\begin{array}{l}\text { - There is no public education on flood risk terms. } \\
\text { - There is no EAP, but there are other warning systems. } \\
\text { - There is no coordination between emergency agencies and } \\
\text { authorities. } \\
\text { - No communication mechanisms to the public. }\end{array}$ & $\begin{array}{r}0 \\
0.25 \\
0.625 \\
1 \\
1.5 \\
24\end{array}$ & $\begin{array}{r}0.9 \\
0.9 \\
0.675 \\
- \\
- \\
-\end{array}$ & $\begin{array}{r}0.3 \\
0.3 \\
0.075 \\
0.055 \\
0.0002 \\
0.0002\end{array}$ & $\begin{array}{r}0.02 \\
0.02 \\
0.014 \\
0.00055 \\
0.0002 \\
0.0001\end{array}$ \\
\hline$C 3$ & $\begin{array}{l}\text { - There is no public education on flood risk terms. } \\
\text { - There is EAP, but it has not been applied yet. } \\
\text { - Some coordination between emergency agencies and authori- } \\
\text { ties (but protocols are not established). } \\
\text { - No communication mechanisms to the public. }\end{array}$ & $\begin{array}{r}0 \\
0.25 \\
0.625 \\
1 \\
1.5 \\
24\end{array}$ & $\begin{array}{r}0.9 \\
0.85 \\
0.6 \\
- \\
- \\
-\end{array}$ & $\begin{array}{r}0.3 \\
0.2 \\
0.07 \\
0.05 \\
0.0002 \\
0.0002\end{array}$ & $\begin{array}{r}0.02 \\
0.015 \\
0.012 \\
0.0005 \\
0.0002 \\
0.0001\end{array}$ \\
\hline$C 4$ & $\begin{array}{l}\text { - There is no public education on flood risk terms. } \\
\text { - EAP is already applied. } \\
\text { - Coordination between emergency agencies and authorities } \\
\text { (there are protocols). } \\
\text { - No communication mechanisms to the public. }\end{array}$ & $\begin{array}{r}0 \\
0.25 \\
0.625 \\
1 \\
1.5 \\
24\end{array}$ & $\begin{array}{r}0.9 \\
0.75 \\
0.5 \\
- \\
- \\
-\end{array}$ & $\begin{array}{r}0.3 \\
0.15 \\
0.04 \\
0.03 \\
0.0002 \\
0.0002\end{array}$ & $\begin{array}{r}0.02 \\
0.01 \\
0.007 \\
0.0003 \\
0.0002 \\
0.0001\end{array}$ \\
\hline$C 5$ & $\begin{array}{l}\text { - There is no public education on flood risk terms. } \\
\text { - EAP is already applied. } \\
\text { - Coordination between emergency agencies and authorities } \\
\text { (there are protocols). } \\
\text { - Communication mechanisms to the public (not checked yet). }\end{array}$ & $\begin{array}{r}0 \\
0.25 \\
0.625 \\
1 \\
1.5 \\
24\end{array}$ & $\begin{array}{r}0.9 \\
0.75 \\
0.5 \\
- \\
- \\
-\end{array}$ & $\begin{array}{r}0.3 \\
0.15 \\
0.0375 \\
0.0275 \\
0.0002 \\
0.0002\end{array}$ & $\begin{array}{r}0.02 \\
0.01 \\
0.0065 \\
0.000275 \\
0.0002 \\
0.0001\end{array}$ \\
\hline C6 & $\begin{array}{l}\text { - There is no public education on flood risk terms. } \\
\text { - EAP is already applied. } \\
\text { - Coordination between emergency agencies and authorities } \\
\text { (there are protocols). } \\
\text { - Communication mechanisms to the public. }\end{array}$ & $\begin{array}{r}0 \\
0.25 \\
0.625 \\
1 \\
1.5 \\
24\end{array}$ & $\begin{array}{r}0.9 \\
0.75 \\
0.475 \\
- \\
- \\
-\end{array}$ & $\begin{array}{r}0.3 \\
0.15 \\
0.035 \\
0.025 \\
0.0002 \\
0.0002\end{array}$ & $\begin{array}{r}0.02 \\
0.01 \\
0.006 \\
0.00025 \\
0.0002 \\
0.0001\end{array}$ \\
\hline$C 7$ & $\begin{array}{l}\text { - Public education. } \\
\text { - EAP is already applied. } \\
\text { - Coordination between emergency agencies and authorities } \\
\text { (there are protocols). } \\
\text { - Communication mechanisms to the public. }\end{array}$ & $\begin{array}{r}0 \\
0.25 \\
0.625 \\
1 \\
1.5 \\
24\end{array}$ & $\begin{array}{r}0.9 \\
0.65 \\
0.4 \\
- \\
- \\
-\end{array}$ & $\begin{array}{r}0.3 \\
0.1 \\
0.02 \\
0.01 \\
0.0002 \\
0.0002\end{array}$ & $\begin{array}{r}0.02 \\
0.0075 \\
0.002 \\
0.0002 \\
0.0002 \\
0.0001\end{array}$ \\
\hline$C 8$ & $\begin{array}{l}\text { - Public education. } \\
\text { - EAP is already applied. It has been proved or used previously. } \\
\text { - Coordination between emergency agencies and authorities } \\
\text { (there are protocols). } \\
\text { - Communication mechanisms to the public. }\end{array}$ & $\begin{array}{r}0 \\
0.25 \\
0.625 \\
1 \\
1.5 \\
24\end{array}$ & $\begin{array}{r}0.9 \\
0.55 \\
0.35 \\
- \\
- \\
-\end{array}$ & $\begin{array}{r}0.3 \\
0.06 \\
0.01 \\
0.005 \\
0.0002 \\
0.0002\end{array}$ & $\begin{array}{r}0.02 \\
0.006 \\
0.0015 \\
0.00015 \\
0.00015 \\
0.0001\end{array}$ \\
\hline$C 9$ & $\begin{array}{l}\text { - Public education. } \\
\text { - EAP is already applied. It has been proved or used previously. } \\
\text { - High coordination between emergency agencies and authori- } \\
\text { ties (there are protocols). } \\
\text { - Communication mechanisms to the public. }\end{array}$ & $\begin{array}{r}0 \\
0.25 \\
0.625 \\
1 \\
1.5 \\
24\end{array}$ & $\begin{array}{r}0.9 \\
0.55 \\
0.35 \\
- \\
- \\
-\end{array}$ & $\begin{array}{r}0.3 \\
0.06 \\
0.008 \\
0.004 \\
0.0002 \\
0.0002\end{array}$ & $\begin{array}{r}0.02 \\
0.006 \\
0.0015 \\
0.000125 \\
0.0001 \\
0.0001\end{array}$ \\
\hline$C 10$ & $\begin{array}{l}\text { - Regular activities and plans for public education. } \\
\text { - EAP is already applied. It has been proved or used previously. } \\
\text { - High coordination between emergency agencies and authori- } \\
\text { ties (there are protocols). } \\
\text { - Communication mechanisms to the public. }\end{array}$ & $\begin{array}{r}0 \\
0.25 \\
0.625 \\
1 \\
1.5 \\
24\end{array}$ & $\begin{array}{r}0.9 \\
0.5 \\
0.3 \\
- \\
- \\
-\end{array}$ & $\begin{array}{r}0.3 \\
0.03 \\
0.005 \\
0.002 \\
0.0002 \\
0.0002\end{array}$ & $\begin{array}{r}0.02 \\
0.005 \\
0.001 \\
0.0001 \\
0.0001 \\
0.0001\end{array}$ \\
\hline
\end{tabular}

Note: Category $C 7$ also used for case studies which correspond to categories $C 8, C 9$ or $C 10$ if dam break occurs with no-hydrologic scenario. 
needs. In this respect, science currently provides us with limited empirical data. Therefore, the questionnaire developed within the SUFRI project, as part of the "Methodology for investigation of risk awareness of the population concerned" (Zechner et al., 2011), provides empirical data on the subjective view of the citizens regarding flooding. Particular attention is paid to the desired communication and information before, during and after a flood (Grossmann and Seiser, 2011).

With the standardized questionnaire, an appropriate instrument is available to investigate the risk awareness of the population. For the survey, a written questionnaire in combination with a personal hand-out and collection has been chosen. The written questionnaire provides the possibility to obtain a wide range of answers; it allows a higher level of sensitive questions due to the higher anonymity, which fosters the honesty of answers, the respondent has more flexibility to fill-out the questionnaire (e.g. time, reconsideration), and external effects through interviewer's attitude and interpretation do not occur. The standardization of the questions and the possibilities for answering facilitate the analysis and evaluation of the level of flood risk awareness for a particular region by using relevant survey practices. Since this method is less time consuming, the costs are lower.

The personal contact at the beginning improves the understanding of the research request and leads to an increase of the return rate, as well as the arrangement of a collection time and date, even if this is at the expense of a high degree of anonymity.

The opinion poll consists of 69 questions and an additional field where the respondent has the chance to give further comments (Grossmann and Seiser, 2011). To counteract the limited answer possibilities, supplementary open questions were added into the questionnaire. Questions are related to natural hazards and floods, consequences of flood events (physical, mental and financial), communication and information, as well as self-protection and individual precautions. In addition, aspects of the current warning situation and emergency management, along with level of information, are included.

However, it is important to keep in mind that the level of awareness changes with the participation of people in the opinion poll.

\subsubsection{Description}

The methodology consists of four different phases:

\section{Phase I - Preparation}

Good preparation on defining the study area is the basis for the success of the opinion poll. For example, the physical measurement parameter for defining the number of households can be related to a potential flood event, at least in the range of the 100-yr flood (this means that all the households taken into consideration for the random sampling are situated in the respective area of a 100-yr flood). A detailed demographic survey of the study area is necessary, i.e. socioeconomic data collection, number of people to investigate, period of time for the survey, etc.

Besides the determination of these "hard facts", consideration of "soft factors" is also important. Therefore, it is necessary to make a survey of existing associations, citizens' initiatives, non-governmental organizations (NGOs), or other groups who may be working in this field. Depending on the local circumstances, an involvement of these groups can be considered, or at least information about the scheduled opinion poll may be provided. To guarantee the success of the opinion poll and further use of the results, the local government has to be involved too.

The opinion poll is implemented at the scale of communities (cities or villages) or counties to get a clear picture of the current risk perception, population requirements and their cooperativeness regarding flood protection measures.

\section{Phase II - Procedure}

Phase II consists of two main steps.

- Distribution: Questionnaires will be handed out faceto-face. The presentations of the questionnaire are conducted along a street or a certain area at different times.

- Collection: The type of collection of the questionnaires is selected depending on local circumstances (e.g. faceto-face, by mail, e-mail or fax).

\section{Phase III - Analysis}

The opinion poll is analyzed using a data base of all questions and corresponding answers, including answers to open and closed questions which can be statistically or qualitatively analyzed, respectively.

In this paper, the analysis has been qualitative. In future works, research on which statistical tools are more suitable to validate and extend the scope of the results should be undertaken.

In addition, hypothesis and connectivity testing of predefined questions for the following subjects has to be done (an example is given for each subject):

- Risk awareness, self-protection and individual precaution (17 hypotheses);

Hypothesis 1: The more knowledge people have about floods, the higher the awareness about the residual risk and the willingness to take self-protection measures in the future.

- Communication and information (9 hypotheses); Hypothesis 26: The younger the persons are, the more they would like to retrieve (obtain) information from the internet. 
- Economic consequences of flood events/insurances (3 hypotheses);

Hypothesis 28: Those previously affected differ from those previously unaffected in their willingness to insure themselves against potential damages from catastrophes in the future.

Consequently, a series of 29 hypotheses was developed in the project. These 29 hypotheses allow detailed analyses concerning correlations between different factors, which means between two or more different questions, e.g. gender and knowledge concerning floods. These hypotheses are generally applicable, depending on results of questions (e.g. if there are enough answers for each correlated question). Also, these hypotheses should be statistically tested when data from future surveys are available.

\section{Phase IV - Follow-up activities}

It is essential to present the results for those who supported and took part in the opinion poll in Phase I (e.g. local government, emergency services, citizens, citizens' initiatives or NGOs). Thus, a positive effect can be obtained, and the public feels that their opinions are taken into account, which could lead to new approaches in flood risk management. Depending on local circumstances and target groups, different forms of communication can be used, e.g. assemblies, newspaper reports or presentations.

\subsection{Integrating social research into quantitative urban flood risk analysis}

\subsubsection{Basis}

The existing risk awareness has to be analyzed to define the Base Case, not only with the aim of estimating current flood vulnerability of the urban area, but also to establish the basis for analyzing how each non-structural measure will influence potential consequences.

Thus, results of the proposed opinion poll in the previous section will provide information to estimate current flood vulnerability and new case scenarios with non-structural measures. These new case scenarios will be compared with the Base Case to inform decision makers when prioritizing flood risk reduction actions.

For the integration of social research data into the methodology for quantitative flood risk analysis described in Sect. 2.1, questions of the opinion poll are assigned to the four main groups of non-structural protection measures defined in Sect. 2.1.2 or to an extra group which collects general information (e.g. age, gender, etc.). These groups are:

- General information (GO),

- Public education (PE),

- Warning systems and emergency management (EM),
- Coordination between authorities and emergency services $(\mathrm{CO})$, and

- Communication to the public (CM).

Table 4 classifies all questions (from Q1 to Q69) into the aforementioned five groups and checkmarks the identified connections between them and parameters defined within the overall methodology for estimating potential consequences.

In pluvial flooding, loss of life depends on population at risk (PAR) and the estimated fatality rates, based not only on the existence of warning systems, flood severity, area and people vulnerability, but also on the percentage of people exposed to the flood $(f)$. Hence, results of the survey will support the estimation of factors shown in Table 4. In addition, the opinion poll provides information on current potential economic costs (e.g. land-use values, indirect costs and the expected reduction of damages by self-protection measures).

In river flooding, results of the opinion poll support the category selected from the classification described in Sect. 2.1.4 ( $C 1$ to $C 10$ ) related to different levels of flood severity understanding depending on the four groups shown in Table 4 (public education, warning systems and emergency management, coordination between actors (e.g. authorities, emergency services, etc.) and communication to the public).

\subsubsection{Evaluation of non-structural measures}

The abovementioned four groups of non-structural protection measures are included in this section to describe how to integrate new information into the risk model (in Phase X). At this point, results of social research will provide information to incorporate the change in risk awareness into the model with the aim of assessing the impact on flood risk reduction.

- Public education (PE):

Public education programmes can reduce flood risk considerably. A better knowledge of the existing risk, emergency management practices, sources of risk, protective measures and procedures in case of flooding can reduce potential flood consequences. An increase in public awareness can be either considered in the analysis as a better flood severity understanding, that is, as a higher category $(C 1-C 10)$ for estimating potential fatalities in river flooding, or as a reduction on population at risk or the percentage of people exposed to the flood due to a more effective response and more rapid evacuation processes.

- Warning systems and emergency management (EM):

The purpose of a flood system is to provide warning on impending flooding and help flood management agencies and the members of flood-prone communities to understand the nature of developing floods so that they can take action to mitigate the flood's effects. A flood warning system is made up of a number of components 
Table 4. Integration of social research into quantitative flood risk analysis.

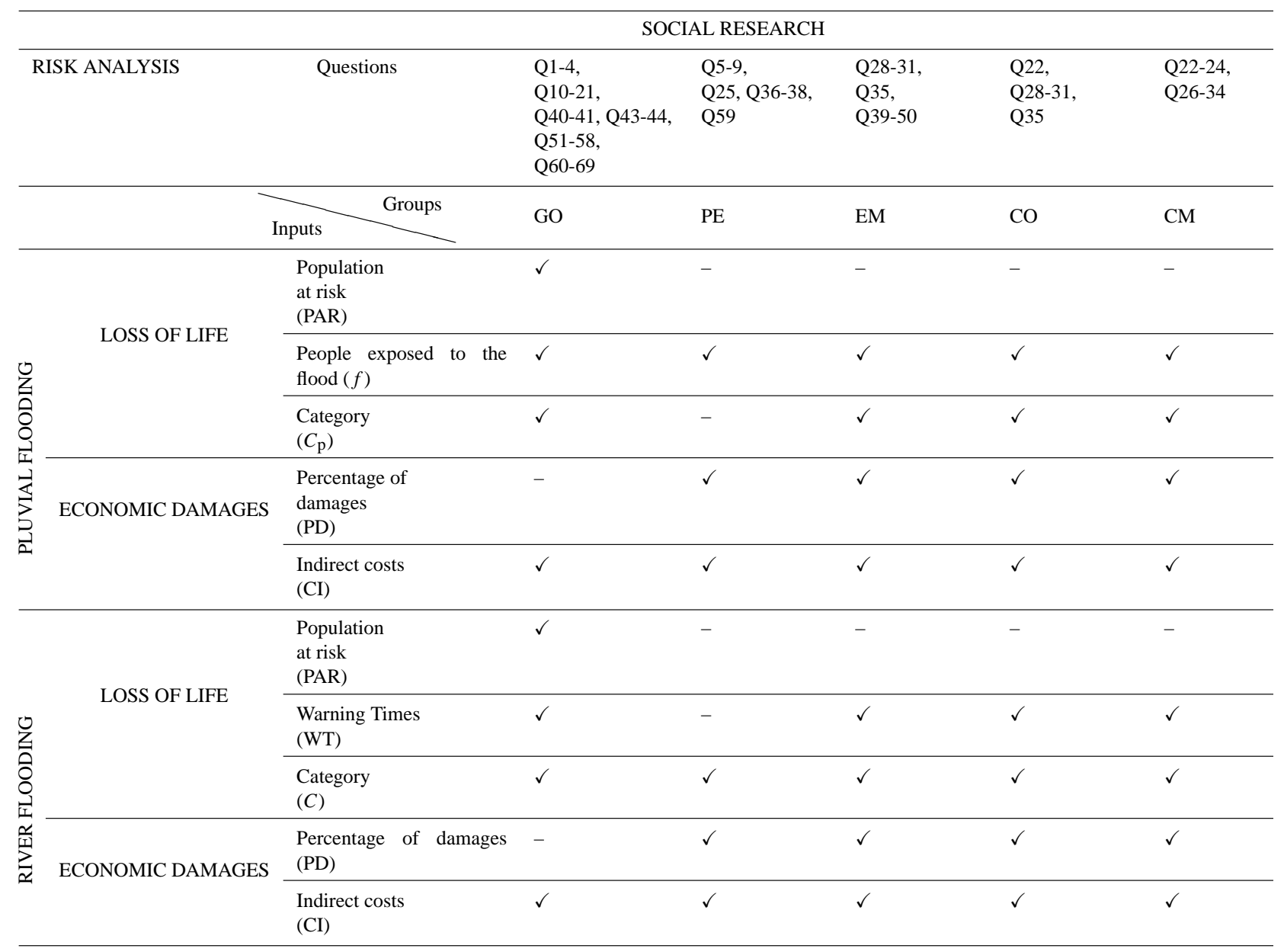

Note: $Q=$ question of the opinion poll, PAR = population at risk, $f=$ percentage of people exposed to the flood, $C_{\mathrm{p}}=$ category for defining the range of fatality rates in pluvial flooding, $\mathrm{PD}=$ percentage of damages in assets, $\mathrm{CI}=$ indirect costs, $\mathrm{WT}=$ warning time; $C=$ category for defining the range of fatality rates in river flooding, $\mathrm{GO}=$ General information; $\mathrm{PE}=$ Public education; $\mathrm{EM}=$ Warning systems and emergency management; $\mathrm{CO}=\mathrm{Coordination}$, and $\mathrm{CM}=\mathrm{Communication}$ to the public.

which must be integrated. These components include (AEMS, 2009):

- monitoring of rainfall and river flows that may lead to flooding,

- prediction of flood severity and the time of onset,

- interpretation of the prediction to determine flood impacts,

- construction of warning messages describing what is happening and will happen, the expected impact and what actions should be taken,

- dissemination of warning messages,

- response to the warnings by involved agencies and community members, and

- review of the warning system after flood events.

The improvement of the effectiveness of existent warning systems or the implementation of advance systems can increase the available warning time and the percentage of people who receive the message during the flood event. In addition, the improvement of emergency management plans can reduce considerably potential consequences. In pluvial flooding, this can be assessed by using a higher category $C_{\mathrm{p}}$ related to the existence of a warning system, and in river flooding by means of a higher category $C$.

- Coordination between emergency agencies and authorities (CO):

A high level of coordination between emergency agencies and authorities will increase the effectiveness of flood emergency management. This will result in prompt responses, larger warning times and efficient evacuating procedures providing shelter and assistance. 


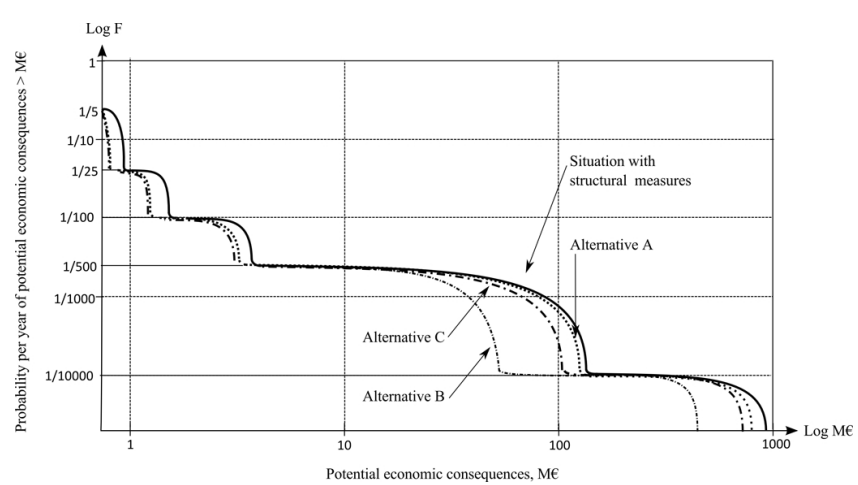

Fig. 5. Example of risk information based on comparison of $F-D$ curves obtained by integrating social research data into quantitative flood risk assessment.

- Communication to the public $(\mathrm{CM})$ :

Risk communication is the basis for an effective flood risk management. The combination of public education and risk communication will provide information to the public, increasing risk awareness and decreasing vulnerability.

Survey data can be considered for estimating potential consequences for the current situation or the impact of a nonstructural measure (or set of measures) based on the relations shown in Table 4. As an example, Fig. 5 shows the $F-D$ curves of a hypothetical analysis including four alternatives (the situation with only structural measures, and alternatives $\mathrm{A}, \mathrm{B}$, and $\mathrm{C}$ ).

Results of the opinion poll can be used to estimate potential consequences for each alternative. For example, if Alternative $\mathrm{A}$ includes the existence of an advanced warning system which increases the available warning time from 1 to $2 \mathrm{~h}$ and the results of the survey show that citizens need less than $1.5 \mathrm{~h}$ to take self-protection measures (such as waterstops, flood defence barriers, etc.), then the expected damages to households should be adapted to an evaluation of Alternative A; consequently, $F-D$ curves will differ from the case with only structural measures to this alternative. Other outcomes of the survey, such as the confidence of people in local authorities, can be included in the estimation of potential consequences of other alternatives such as new emergency procedures or planning policies.

In conclusion, after evaluating the effect of a nonstructural measure (or set of measures) on the estimation of potential consequences by including the evaluation of outcomes of a social research survey to characterize public risk awareness, the flood risk can be quantified to represent $F-N$ and $F-D$ curves. These curves can be used to analyze the impact of different measures on the magnitude and frequency of consequences. Conclusions of this comparison will support decision making in developing a proposal of non-structural protection measures.

\section{Case studies: Benaguasil and Lodi}

The integration of social research data into flood risk analysis has been applied to two case studies (Fig. 6), Benaguasil (Spain) and Lodi (Italy), as examples of pluvial and river flooding, respectively. This section includes a short description of both urban areas (Sect. 3.1), outlines results of the public opinion poll (Sect. 3.2) and their integration into risk analysis (Sect. 3.3), and further, outlines conclusions to support decision making on non-structural protection measures (Sect. 3.4).

\subsection{Description}

Benaguasil is located in the east of Spain, $20 \mathrm{~km}$ inland from the city of Valencia, placed in the catchment area of the Turia River. The town is not affected by river floods as it is located far from the river bed. Thus, flood risk is mainly due to pluvial flooding as a result of the low capacity of the drainage system that reaches its maximum capacity with precipitation rates higher than $20 \mathrm{~mm}$ in a few minutes, flooding garages, ground floors, houses and roads.

The exceedance of the capacity of the drainage system produces flooding of basements and ground floors of many houses every year and, consequently, significant economic damages. Furthermore, new residential areas have been connected directly to the existing drainage system. Consequently, flooding problems have increased in the last years.

Lodi is located in the north of Italy, crossed by the Adda River with a dam located at Olginate $75 \mathrm{~km}$ upstream of the town. The city of Lodi has been flooded during the last century 30 times (ten of these were caused by the main tributaries of Adda River, Brembo and Serio, in the 60's). The most recent flood event occurred in November 2002, with a peak discharge around $1800 \mathrm{~m}^{3} \mathrm{~s}^{-1}$ with an estimated return period of $100 \mathrm{yr}$.

In both cases, flood risk has been analyzed in two situations: first, the current situation of the urban area, and second, the situation with the implementation of non-structural measures concerning public education and improved warning systems.

\subsection{Social research}

In Benaguasil, 201 households with approximately 800 residents are located within the potential flooded area related to the 100-yr rainfall event. In June 2010, these households were considered for the survey. Interviews were carried out personally with a high return rate of $32 \%$ (Zechner et al., 2011).

More women $(64 \%)$ than men $(36 \%)$ took part in the opinion poll (with a total of 33 interviewees). With an average age of $40 \mathrm{yr}$ in this urban area, $92 \%$ of the respondents were older than $30 \mathrm{yr}$, with a percentage of $21 \%$ older than $60 \mathrm{yr}$. There is a wide distribution of the highest 
Table 5. Excerpt of questions (Q) and hypotheses $(\mathrm{H})$ chosen for the analysis of Benaguasil and Lodi case studies referring to two groups of non-structural measures: public education $(\mathrm{PE})$ and communication to the public (CM).

\begin{tabular}{|c|c|c|c|}
\hline ID & Question/Hypothesis & $\mathrm{PE}$ & $\mathrm{CM}$ \\
\hline Q5 & How would you rate your personal knowledge about floods and their causes? & $\checkmark$ & \\
\hline Q22 & How much time do you need to prepare sufficiently for a flood? & & $\checkmark$ \\
\hline Q24 & How would you like to obtain information in case of a flood event? & & $\checkmark$ \\
\hline Q25 & $\begin{array}{l}\text { Rate the following statements: I can assess flood risk well; Due to a lack of } \\
\text { information, the feeling of insecurity may arise; ... }\end{array}$ & $\checkmark$ & \\
\hline Q26 & $\begin{array}{l}\text { How reasonable are the following means of communication to keep oneself } \\
\text { informed on a regular basis about flood issues: ... }\end{array}$ & & $\checkmark$ \\
\hline Q28 & How well informed did you feel during the last flood event? & & $\checkmark$ \\
\hline Q29 & How long did it take between the first warnings and the onset of the flood? & & $\checkmark$ \\
\hline Q30 & This time span was ... & & $\checkmark$ \\
\hline Q36 & Do you know concrete measures to protect yourself in case of flood? & $\checkmark$ & \\
\hline Q38 & Where have you learned about these measures? & $\checkmark$ & \\
\hline H6 & $\begin{array}{l}\text { The estimated meaningfulness of self-protection measures and the willingness } \\
\text { to take self-protection measures in the future depend on information access. }\end{array}$ & $\checkmark$ & \\
\hline H19 & $\begin{array}{l}\text { Dependent on the level of education, the need for information differs in case of } \\
\text { floods. }\end{array}$ & $\checkmark$ & \\
\hline $\mathrm{H} 26$ & $\begin{array}{l}\text { The greater the knowledge of a person with regard to floods, the shorter the } \\
\text { necessary time span in order to be prepared sufficiently for floods. }\end{array}$ & & $\checkmark$ \\
\hline
\end{tabular}

educational achievement, with $36 \%$ finishing compulsory education, $21 \%$ professional training, $14 \%$ upper secondary school, and $21 \%$ university.

In Lodi, 3000 residents are living in the area of the 100-yr flood (750 households). Within this group, every 3rd household was interviewed in October and November 2010 personally, resulting in a high return rate of $64 \%$.

More men $(62 \%)$ than women $(38 \%)$ took part in the opinion poll (with a total amount of 188 questionnaires). In this case, $98 \%$ of the respondents were older than $30 \mathrm{yr}$, with a percentage of $43 \%$ older than $60 \mathrm{yr}$. The highest educational achievement in Lodi differs from those in Benaguasil, with $28 \%$ of the interviewees of the former having finished compulsory education, $8 \%$ professional training, $44 \%$ upper secondary school, and $14 \%$ university.

With the aim of providing information for flood risk analysis and capturing the influence of the non-structural measures regarding public education and improved warning systems, a set of questions of the opinion poll have been selected concerning two of the four groups identified in Sect. 2.1.2 (public education (PE) and communication to the public (CM)).

Table 5 shows selected questions and hypotheses regarding Benaguasil and Lodi case studies from Jöbstl et al. (2011). These questions have been related in this paper to the aforementioned groups: public education (PE) and communication to the public (CM). The three hypotheses listed in Table 5 were obtained from data analysis of surveys.
Questions shown in Table 5 are then classified following the aforementioned two groups: public education (PE) and communication to the public (CM). Two examples of results of the opinion poll are also given in this section (Figs. 7 and 8).

\subsubsection{Public education (PE)}

Question Q5 shows current risk perception and knowledge of the interviewed inhabitants of Benaguasil and Lodi. In both cases, more than $65 \%$ rate their knowledge about floods very good, mostly good or somewhat good.

The general knowledge about flood risk and the individual perception of the risk was analyzed through the answers to question Q25 (Fig. 7).

The individual knowledge of floods and the associated risk presented differences between both cases: whereas in $\mathrm{Be}-$ naguasil the majority (69\%) can evaluate flood risk well; in Lodi, only $7 \%$ agree with this. In addition, $68 \%$ feel uncomfortable because of missing information.

However, results of questions Q36 and Q38 (Table 5) show the knowledge about self-protection measures differs in these two case studies; in Benaguasil, $73 \%$ of the respondents know such measures $(83 \%$ gain their knowledge from friends and relatives), as opposed to $38 \%$ in Lodi (where only $34 \%$ obtained information from relatives, as most of the people in Lodi stated to have other information sources). Results in Benaguasil show that measures are 


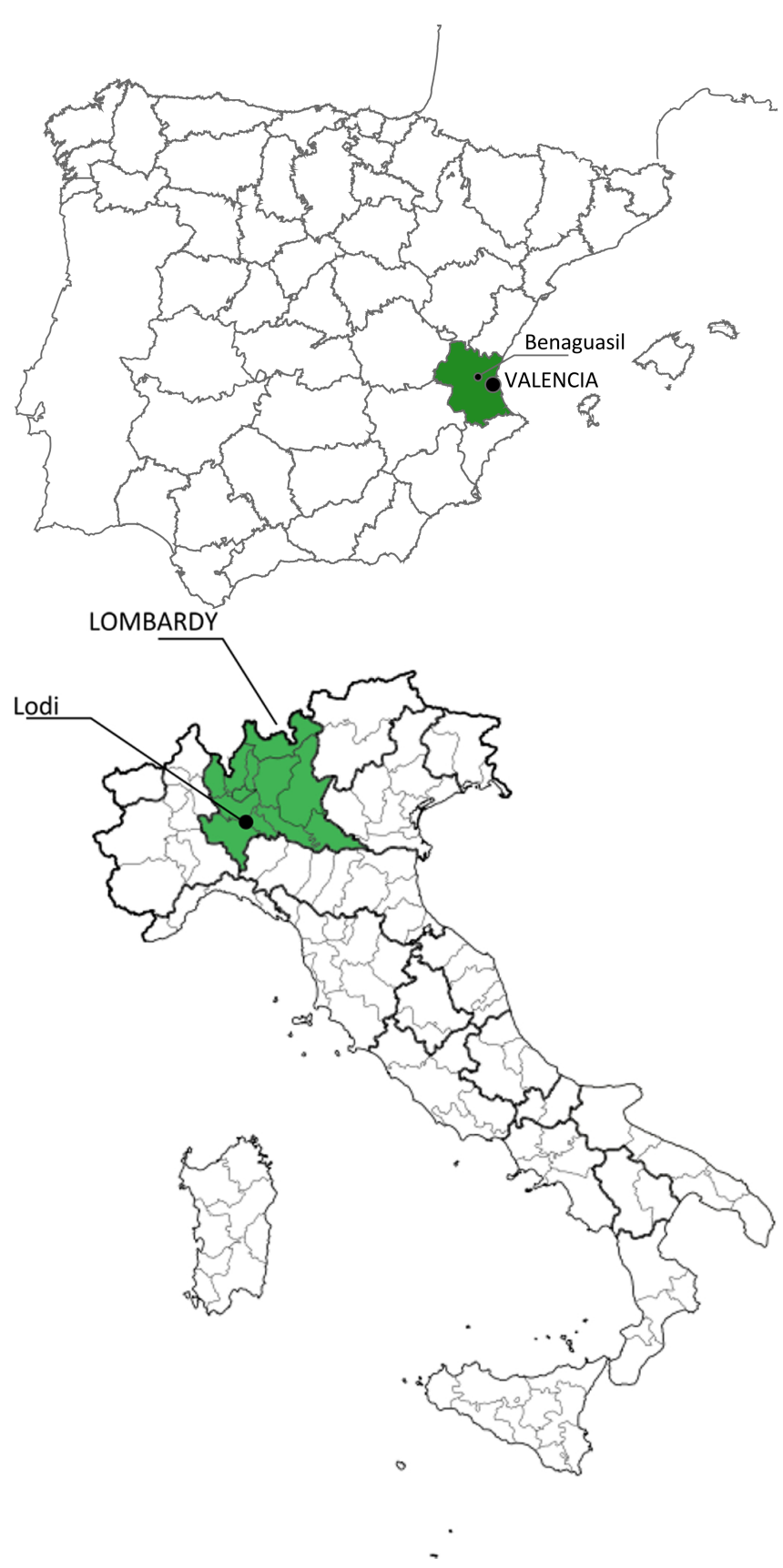

Fig. 6. Location of Benaguasil in Valencia (Spain) and Lodi in Lombardy (Italy).

estimated effective or very effective by $62 \%$ of the respondents. Only a few think that these measures are little or not effective $(13.8 \%)$. However, most of respondents are not willing to take self-protection measures in the future. On the contrary, in Lodi self-protection measures are estimated not, little or partially effective by approximately $62 \%$ of the respondents. Only a few think that these measures are very effective $(24.5 \%)$, but despite this low rate, approximately $80 \%$ of those interviewed intend to take self-protection measures in the future. These results show that the estimated meaningfulness of self-protection measures may vary depending on the case study and the willingness to take these measures in the future will depend on the information access (hypothesis H6, Table 5), risk perception and also on public education.

In addition to the aforementioned results, no difference regarding the level of risk awareness had been found depending on gender or level of education. However, the preferred means to obtain information depended on the level of education (hypothesis H19, Table 5).

\subsubsection{Communication to the public (CM)}

Due to the influence of warning systems on potential consequences, it is important to know, for example, public perception of the required warning time to prepare self-protection measures.

In Benaguasil, $89 \%$ of interviewees considered that they would need less than $2 \mathrm{~h}$ to prepare themselves sufficiently for a flood (questions Q22, Q29 and Q30, Fig. 8). However, in Lodi this only applies for $7 \%$. Nearly half of Lodi's inhabitants believe they would need more than $6 \mathrm{~h}$, but $53 \%$ of them had only up to $0.5 \mathrm{~h}$ during the last flood, and $16 \%$ between 0.5 and $2 \mathrm{~h}$. The available time between the first warning and the onset of the flood was far too short for $82 \%$ of all interviewed people.

From results of these questions, it was concluded in both cases that the greater the knowledge of a person with regard to floods, the shorter the time span needed to be prepared sufficiently is (H26, Table 5).

Regarding the influence of communication and warning systems on risk reduction, it has to be considered which types of communication are preferred by the public in order to develop adequate communication strategies. On this point, there are significant differences between both cases (Table 5, question Q24); in Lodi, information by emergency services $(85 \%)$ and community or local councils $(67 \%)$ are preferred, but in Benaguasil most prefer to get information by the media $(62 \%)$ or Internet $(31 \%)$.

In Benaguasil, advertisements in the media $(71 \%)$ and onsite information centres $(50 \%)$ as well as websites on the Internet $(46 \%)$ are the preferred communication means to keep oneself informed on a regular basis (see Table 5, question Q26). In Lodi, the analysis has not shown such a clear picture, but on-site information centres (40\%) and advertisements in the media $(37 \%)$ are also preferred.

In addition, regarding the information provided to people during last flood events, most of the interviewees felt very badly informed (Table 5, question Q28), Lodi with $85 \%$ and Benaguasil with $68 \%$. 


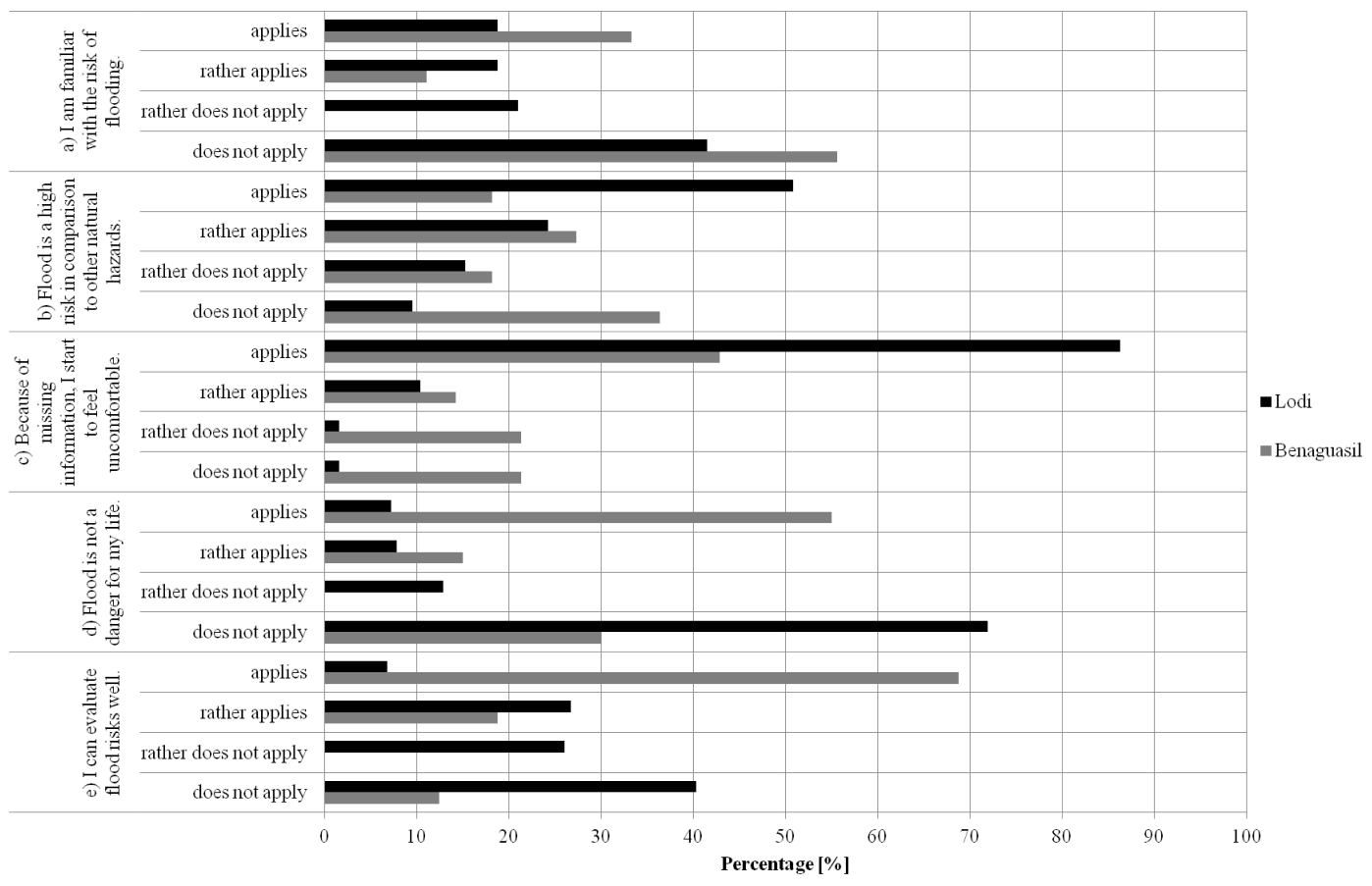

Fig. 7. General knowledge about flood risk. Note: (a) I am familiar with the risk of flooding (Lodi $n=176$, Benaguasil $n=9$ ); (b) flood is a high risk in comparison to other natural hazards (Lodi $n=177$, Benaguasil $n=11$ ); (c) because of missing information, I start to feel uncomfortable (Lodi $n=182$, Benaguasil $n=14$ ); (d) flood is not a danger for my life (Lodi $n=178$, Benaguasil $n=20$ ); (e) I can evaluate flood risks well (Lodi $n=176$, Benaguasil $n=16$ ).

\subsection{Flood risk analysis}

\subsubsection{Benaguasil}

Risk due to pluvial flooding has been assessed for Benaguasil by defining two analyses: first, the study of the current situation (denoted as Base Case), and second, the effect of nonstructural measures regarding a public education program on flood risk and the existence of warning systems (denoted as PFR+WS-Case).

On one hand, the public education program would include the following aspects:

- Annual information campaigns and workshops for action forces and the public;

- Design of a website with updated information and advice to the public;

- Regular publications in the local bulletin; and

- An information desk at the Town Council.

On the other hand, the components of the warning system are:

- Daily reports at a specific information desk;
- Information on prediction or monitoring of rainfall events provided by Civil Protection, the Spanish Agency of Meteorology or local services of the City Council;

- Interpretation of the prediction (identification of the corresponding level of meteorological risk alarm, vulnerable areas, and expected hydraulic characteristics);

- Specific warning messages describing what is happening, the expected impact and what actions should be taken depending on the level of meteorological risk alarm;

- Dissemination of warning messages, transmitted by means of loudspeakers located at the urban area; and

- Annual drills and tests to verify efficiency of warning messages.

Based on the connections provided in Sect. 2.3 to integrate social research data into flood risk analysis (Table 4) with the aim of evaluating the current situation (Base Case) and the effect of non-structural measures (PFR+WS-Case), Table 6 shows the impact of results of social research data on the estimation of potential fatalities for the case study of Benaguasil.

Main aspects of the analysis are summarized: 


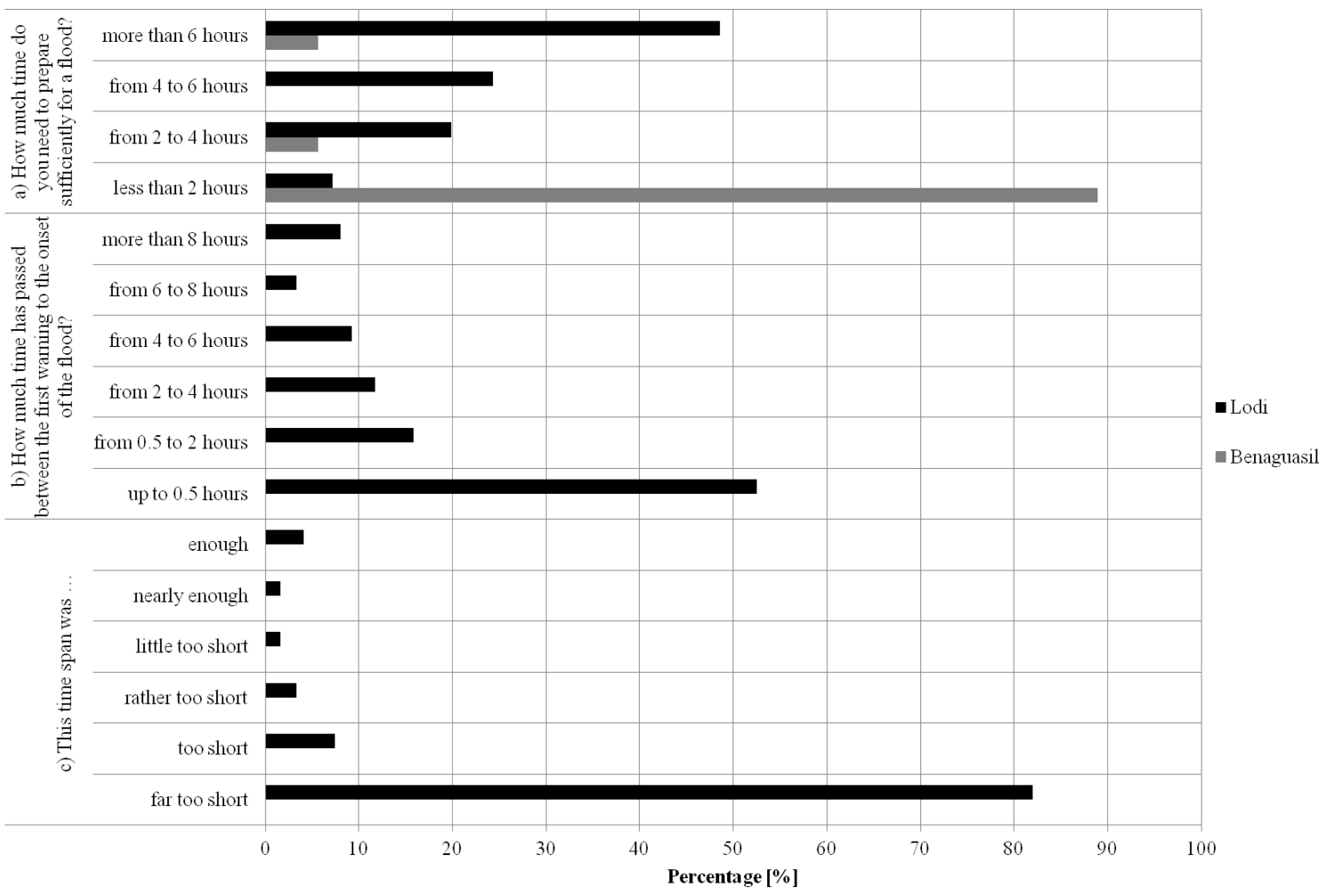

Fig. 8. (a) Time to prepare for a flood; (b) time passed between warning and onset of flood, and (c) evaluation of the time span. Note: (a) Lodi $n=181$, Benaguasil $n=18$; (b) Lodi $n=120$, Benaguasil $n=-$, and, (c) Lodi $n=122$, Benaguasil $n=-$.

Table 6. Integration of social research data into flood risk analysis to estimate potential consequences for the case study of Benaguasil.

\begin{tabular}{|c|c|c|c|c|c|c|}
\hline \multicolumn{7}{|c|}{ BENAGUASIL } \\
\hline & \multicolumn{2}{|c|}{ Inputs for risk analysis } & $\begin{array}{l}\text { Public edu- } \\
\text { cation (PE) }\end{array}$ & $\begin{array}{l}\text { Communication } \\
\text { to the public } \\
(\mathrm{CM})\end{array}$ & $\begin{array}{l}\text { Base Case } \\
\text { (current situation) }\end{array}$ & $\begin{array}{l}\text { PFR+WS-Case } \\
\text { (including non- } \\
\text { structural measures) }\end{array}$ \\
\hline \multirow{5}{*}{ 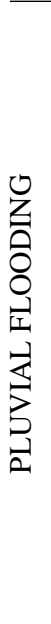 } & \multirow[t]{3}{*}{ LOSS OF LIFE } & $\begin{array}{l}\text { Population at } \\
\text { risk } \\
(\mathrm{PAR})\end{array}$ & - & - & - & - \\
\hline & & $\begin{array}{l}\text { People exposed } \\
\text { to the flood } \\
(f)\end{array}$ & $\checkmark$ & $\checkmark$ & $\begin{array}{l}\text { People exposed to the } \\
\text { flood } \\
f=P \exp / \mathrm{PAR}\end{array}$ & $\begin{array}{l}\text { People exposed } \\
\text { to the flood } \\
0.5 \times f\end{array}$ \\
\hline & & $\begin{array}{l}\text { Category } \\
\left(C_{\mathrm{p}}\right) \\
\end{array}$ & - & $\checkmark$ & $C_{\mathrm{p} 1}$ & $C_{\mathrm{p} 3}$ \\
\hline & \multirow[t]{2}{*}{$\begin{array}{l}\text { ECONOMIC } \\
\text { DAMAGES }\end{array}$} & $\begin{array}{l}\text { Percentage of } \\
\text { damages } \\
\text { (PD) }\end{array}$ & $\checkmark$ & $\checkmark$ & $\begin{array}{l}\text { PD depends on } \\
\text { water depth }\end{array}$ & $\begin{array}{l}\text { Reduction of PD } \\
\text { based on water depth } \\
\text { and waterstops } \\
(y<1.2 \mathrm{~m})\end{array}$ \\
\hline & & $\begin{array}{l}\text { Indirect costs } \\
(\mathrm{CI})\end{array}$ & $\checkmark$ & $\checkmark$ & $27 \%$ & $27 \% *$ \\
\hline
\end{tabular}

* Although public education and improved warning systems would in some cases reduce indirect costs, no differences are considered for the Benaguasil case.

Note: PAR = population at risk; $f$ = percentage of people exposed to the flood with respect to population at risk; $C_{\mathrm{p} 1}=$ category for defining fatality rates for the Base Case; $C_{\mathrm{p} 3}=$ category for defining fatality rates for the PFR+WS-Case; $\mathrm{PD}=$ percentage of damages to assets which depends on water depth and the effect of waterstops as self-protection measures; and $\mathrm{CI}=$ indirect costs as a percentage of direct costs. 
- The population of Benaguasil is estimated to be 11144 inhabitants (2010). Combining daily and seasonal variations (approx. 200 people), four time categories are established to estimate the population at risk.

- Seven flood events are defined, relating to maximum daily rainfall rates and annual probabilities of exceedance ranging from 2 to $100-y r$ return periods.

- Benaguasil is mainly divided into residential zones, except for an industrial area located in the south. Three land uses are identified and related to different reference costs to estimate economic damages.

- Runoff rates have been obtained for each flood event based on the Rational Method (Témez, 1991) adapted to urban catchments. Six catchments areas have been identified, obtaining flooded areas and runoff coefficients based on land-use characteristics and the capacity of the existing drainage network. Flood hydraulic characteristics are estimated to obtain flood severity levels and fatality rates, as well as the percentage of damages based on depth-damage curves (COPUT, 2002).

- The effect of a public education programme on flood risk and the existence of warning systems is analyzed based on social research data as described in Table 6, defining the category $C_{\mathrm{p} 3}$ (as a result of the existence of warning systems), a reduction on the percentage of people exposed to the flood (due to an improved flood severity understanding), and establishing a reduction of the percentage of damages to households (i.e. a better knowledge of self-protection measures and higher warning times will reduce economic damages, as it was obtained from social research that citizens need approximately $2 \mathrm{~h}$ to prepare sufficiently for a flood).

As it has been described in Sect. 2.1, the required information for characterizing all possible flood events and potential consequences can be incorporated into a risk model. The information needed to feed the model, given in Table 7, is related to rainfall events, hydraulic characteristics of the flood, potential consequences in terms of loss of life and economic damages, etc. Table 7 describes the categories of the information used for the case study of Benaguasil. Risk results are compared and represented in Figs. 9 and 10.

As potential fatalities in the case of river flooding are usually higher than in pluvial flooding, in Benaguasil economic risk has more significance than societal risk. However, there is no doubt that public education and warning systems have an effect on risk reduction in both $F-N$ and $F-D$ graphs.

\subsubsection{Lodi}

River flooding has been assessed for the Lodi case. Two analyses are defined: first, the study of the current situation with structural measures (levees nearby the urban area, without considering Olginate dam), denoted as Base Case, and second, the situation after the application of public education and warning systems, denoted as PFR+WS-Case.

On one hand, the public education program, set by Civil Protection, would include the following aspects:

- Annual information campaigns at schools;

- Guidelines, updates and training courses for public administration workers and volunteers;

- Practical exercises to test the response of action forces; and

- Organization and coordination of volunteers groups.

On the other hand, specific procedures for communication and warning would be applied, such as:

- Identification of potential flooded areas based on the "Program of the Hydrogeological Assessment (PAI)" of Po River and all its tributaries, by the Po River Agency in 2001;

- Definition of the "alarm" if the Po level reaches a specified water level;

- Specific messages to be transmitted by fax to local authorities;

- Specific messages to the population to be displayed on specific notice boards; and

- Specific messages to the population to be announced by sirens.

As it has been described for Benaguasil and based on the connections provided in Sect. 2.3 to integrate social research data into flood risk analysis (Table 4), Table 8 shows the impact of results of social research data on the estimation of potential fatalities for the Lodi case.

Social research results revealed a medium-high level of risk awareness, but no public education campaigns have been performed yet. In addition, the available warning times in past flood events were too short, and, consequently, category C5 for estimating potential loss of life has been considered for the Base Case.

Main aspects of the analysis for Lodi are summarized below:

- Daily and seasonal variability of the population in Lodi (42737 inhabitants).

- Eight flood events for return periods from 2 to $500 \mathrm{yr}$ were used, based on flow measures recorded at four stations in the basin to estimate flood wave characteristics (discharge vs. duration) and using the Gumbel and GEV (Generalized Extreme Value) probability distributions to evaluate the discharges for an assigned return period. 
Table 7. Categories of information for the case study of Benaguasil.

\begin{tabular}{ll}
\hline Category & Content \\
\hline General & To incorporate daily variability of population: includes probabilities of flood occuring during the day or at night. \\
General & $\begin{array}{l}\text { To incorporate seasonal variability of population: includes probabilities of flood occuring in summer or winter. } \\
\text { Four time categories are defined (TC1: summer/day, TC2: summer/night, TC3: winter/day, and TC4: winter- } \\
\text { night). } \\
\text { Toads } \\
\text { To incorporate rainfall events which result in pluvial flooding in the urban area; includes probabilities of occur- } \\
\text { rence in terms of return periods }(T) \text { and annual exceedance probabilities. }\end{array}$ \\
Constem response & $\begin{array}{l}\text { To incorporate hydraulic characteristics of the flood for each rainfall event; includes peak runoff rates }(Q), \\
\text { water depths, velocities, and flooded areas. }\end{array}$ \\
& $\begin{array}{l}\text { To incorporate consequences in terms of potential loss of life depending on flood hydraulic characteristics, flood } \\
\text { severity levels, people exposed to the flood, and fatality rates. Relates number of potential fatalities }(N) \text { to flood } \\
\text { characteristics }(Q) \text { and time categories (TC). }\end{array}$ \\
& $\begin{array}{l}\text { To incorporate consequences in terms of potential economic damages depending on flood hydraulic character- } \\
\text { istics, depth-damage curves, and land uses. Relates potential economic costs }(C T) \text { to flood characteristics }(Q) \\
\text { and time categories (TC). }\end{array}$ \\
\hline
\end{tabular}

Table 8. Integration of social research data into flood risk analysis to estimate potential consequences in Lodi.

\begin{tabular}{|c|c|c|c|c|c|c|}
\hline \multicolumn{7}{|c|}{ LODI } \\
\hline & \multicolumn{2}{|c|}{ Inputs for risk analysis } & $\begin{array}{l}\text { Public educa- } \\
\text { tion (PE) }\end{array}$ & $\begin{array}{l}\text { Communication } \\
\text { to the public } \\
(\mathrm{CM})\end{array}$ & $\begin{array}{l}\text { Base Case } \\
\text { (current situa- } \\
\text { tion) }\end{array}$ & $\begin{array}{l}\text { PFR }+ \text { WS- } \\
\text { Case (including } \\
\text { non-structural } \\
\text { measures) }\end{array}$ \\
\hline \multirow{5}{*}{ 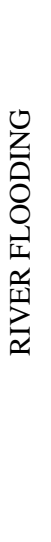 } & \multirow[t]{3}{*}{ LOSS OF LIFE } & $\begin{array}{l}\text { Population at risk } \\
\text { (PAR) }\end{array}$ & - & - & - & - \\
\hline & & $\begin{array}{l}\text { Warning Times } \\
\text { (WT) }\end{array}$ & $\checkmark$ & $\checkmark$ & $\begin{array}{l}\text { Values from } \\
\text { hydraulic } \\
\text { studies }\end{array}$ & $\begin{array}{l}\text { Values from } \\
\text { hydraulic } \\
\text { studies* }\end{array}$ \\
\hline & & $\begin{array}{l}\text { Category } \\
(C)\end{array}$ & - & $\checkmark$ & $C 5$ & $C 9$ \\
\hline & \multirow[t]{2}{*}{$\begin{array}{l}\text { ECONOMIC } \\
\text { DAMAGES }\end{array}$} & $\begin{array}{l}\text { Percentage of damages } \\
\text { (PD) }\end{array}$ & $\checkmark$ & $\checkmark$ & $\begin{array}{l}\text { PD depends on } \\
\text { water depth }\end{array}$ & $\begin{array}{l}\text { Reduction of } \\
\text { PD based on } \\
\text { water depth } \\
\text { and waterstops } \\
(y<1.2 \mathrm{~m})\end{array}$ \\
\hline & & Indirect costs $(\mathrm{CI})$ & $\checkmark$ & $\checkmark$ & $20 \%$ & $10 \%$ \\
\hline
\end{tabular}

* Despite the expected increase in warning times, no differences are considered for Lodi case due to the complexity of estimating its estimation for this case study. Note: $C 5=$ category for defining fatality rates for the Base Case (see Table 3 ); $C 9=$ category for defining fatality rates for the PFR + WS-Case; PD $=$ percentage of damages in assets which depends on water depth and the effect of waterstops as self-protection measures (Parker et al., 2005); and CI =indirect costs as a percentage of direct costs.

- Flooded areas were computed by a 2-D-model based on shallow water equations written in conservative form (Cunge et al., 1990).

- Two land-use categories are considered: residential and agricultural areas.

- Population at risk was decreased by a factor of 2.53 by taking into account building typologies in Lodi.
- Economic losses were estimated by multiplying a reference cost with the percentage of damages from ad hoc depth-damage curves based on data of the 2002 flood.

Input data needed to feed the risk model was related to rainfall events, peak discharges at the river, hydraulic characteristics of the flood, potential consequences in terms of loss of life and economic damages, etc. The main differences with the case study of Benaguasil concern the nature of the system response, in particular to the hydraulic characteristics of the 


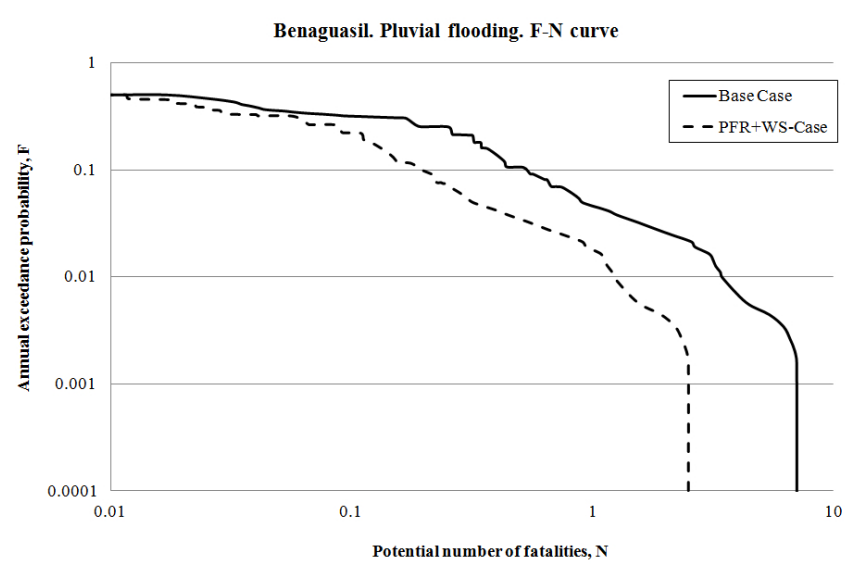

Fig. 9. $F-N$ curve for Benaguasil: pluvial flooding. Base Case and PFR+WS-Case.

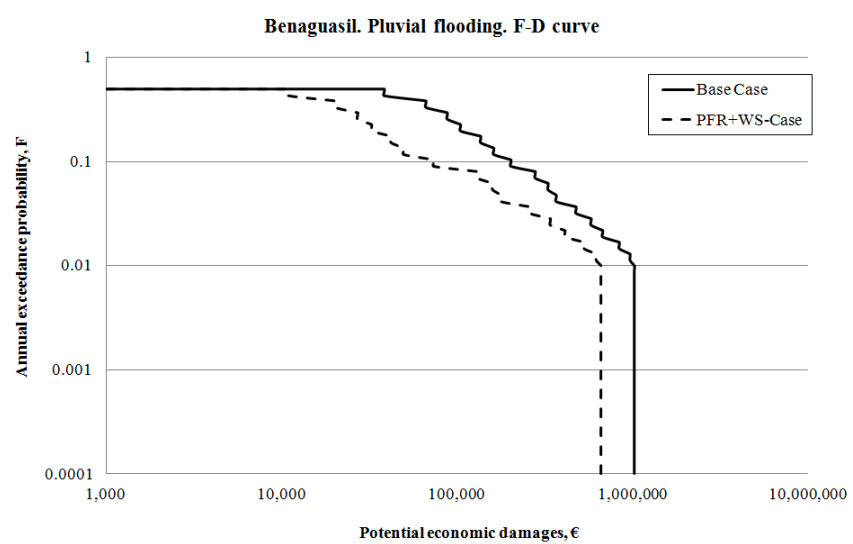

Fig. 10. $F-D$ curve for Benaguasil: pluvial flooding. Base Case and PFR+WS-Case.

flood due to river flooding, including water depths, velocities, flooded areas and peak discharges at the river. Results are compared and represented in the $F-N$ and $F-D$ curves shown in Figs. 11 and 12.

Figure 11 shows that the $F-N$ curve for the PFR+WSCase captures the effect on flood risk of the existence of a public education programme and warning system. During the 2002 flood, having an estimated return period of $100 \mathrm{yr}$, the existence of these non-structural measures would have reduced flood risk to one tenth.

Data from the Lodi Town Council stated that there were $15949800 €$ of damages during the 2002 flood. Figure 12 illustrates that the $F-D$ curve for the current situation shows a similar level of potential economic damages for the same probability of occurrence, and economic costs would be reduced by implementing non-structural measures of public education and warning (resulting in higher levels of selfprotection and lower damages).

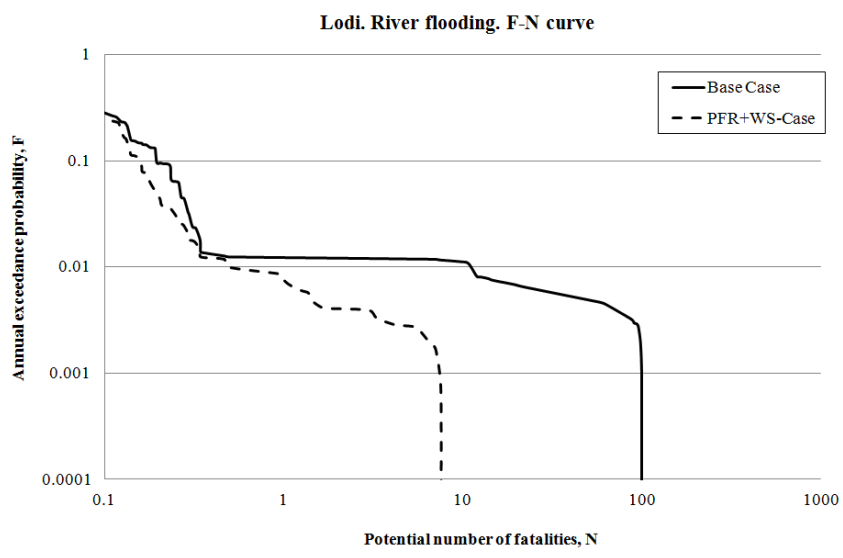

Fig. 11. $F-N$ curve for Lodi: river flooding. Base Case and PFR+WS-Case.

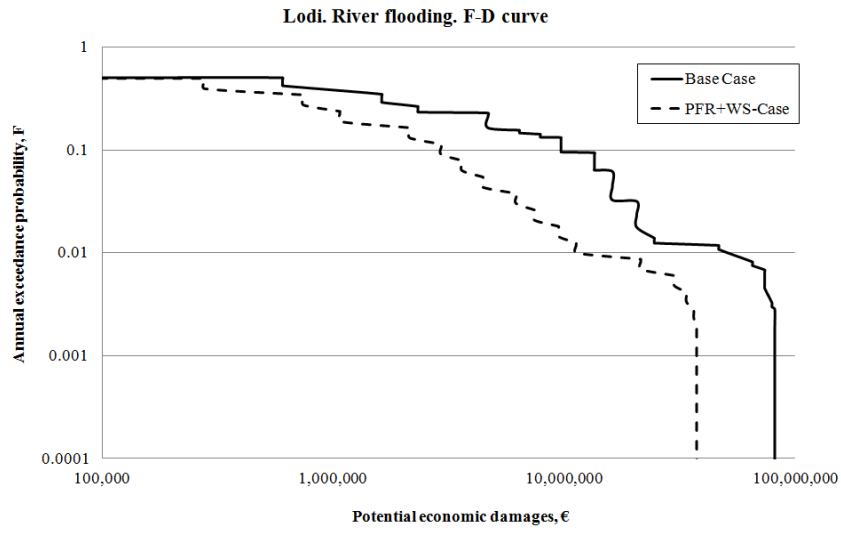

Fig. 12. $F-D$ curve for Lodi: river flooding. Base Case and PFR+WS-Case.

\subsection{Decision making on non-structural protection measures}

The obtained results illustrate, in both case studies, the impact on risk reduction of the implementation of nonstructural measures concerning public education and warning systems.

Results of social research have supported the estimation of inputs for the analysis, and help to identify the population's needs and preferred communication means in order to develop adequate communication strategies and campaigns providing information to select adequate procedures and increase risk awareness.

In addition, social research supports the estimations carried out to perform alternative analyses by evaluating the existing public awareness and the expected effect of public education campaigns on flood severity understanding. Thus, the preferred communication means can be identified as provided in Table 9 for the Benaguasil and Lodi cases. 
Table 9. Preferred communication types in Benaguasil and Lodi case studies.

\begin{tabular}{lll}
\hline & Benaguasil & Lodi \\
\hline Preferred information source & Advertisement in the media & Emergency Services \\
in case of flooding & Sites on the Internet & Community/Local councils \\
Preferred communication to keep oneself & Advertisement in the media & Community/Local councils \\
informed on a regular basis about flood issues & On-site information centres & Emergency services \\
& Sites on the Internet & \\
\hline
\end{tabular}

Once social research results have been used to characterize preferred means of information or communication to the public or other aspects of public risk awareness, different non-structural measures, strategies or alternatives for risk reduction can be assessed by using the methodology described in Sect. 2.1 and the resulting $F-N$ and $F-D$ curves.

At this point, it has to be remarked that probability estimates for different alternatives should be assigned by an expert group/consultation based on results of social research and the analysis of the current situation. Whether resources are available for that or if it has to be done through a smaller group, detailed justification of the reason for such elicitation should be clearly provided (Ayyub, 2001).

When quantitative risk results through alternative analysis are displayed using $F-N$ and $F-D$ curves, it is possible to see the noticeable impacts of the structural and non-structural measures as compared to the current risk. This display of information can help to support decisions regarding the definition of information campaigns, warnings, and communication procedures, etc.

As an example, in the Lodi case, further analyses have shown that there is no significant relation between the knowledge of a person with regard to flood and the necessary time span in order to be prepared sufficiently for floods. Therefore, reducing the flood risk only by setting public education measures may not have a direct impact on the necessary warning time (i.e. although people know about the risk and the possibility of self-protection measures, it does not reduce the necessary time for preparation). Increase of the warning time also must be a part of emergency management (not only to know about the existence of measures, but also to know how to use them efficiently).

For further detail of justification of prioritization among different alternatives, proper indicators should be developed, e.g. following dam safety examples (Bowles, 2004; Munger et al., 2009). This cost-effective approach will require a detailed budget of any alternative and the achieved risk reduction. The annual economic risk reduction can be subtracted from the annual cost of the measure and then divided by the societal risk reduction, which is beyond the scope of this paper (more case studies and measures would be needed), before a formal proposal on a cost-effective post-processing analysis can be validated.

\section{Conclusions and further research}

This paper has presented an approach to integrate social research data into flood risk analysis with the aim of supporting decision making on non-structural protection measures.

This approach is mainly focused on the application of two methodological pieces developed within the SUFRI project that allow qualification of flood risk in urban areas, evaluating different case scenarios in order to compare them with the current situation and the impact of non-structural measures on risk reduction.

Social research data analysis revealed the importance of communication and information strategies as well as selfprecaution and warning systems from the point of view of affected people. The development of public education, coordination, communication and emergency management strategies can be reinforced by the outcomes of opinion polls.

Furthermore, common tendencies in the individual flood risk understanding between case studies have been analyzed (a data set of five case studies has been developed within the SUFRI project). However, some differences have been found, and this confirms clearly the need for a survey based on the specific characteristics of the urban area, defining a special strategy for each case study. Though the scope of this work has been limited to qualitative analysis of the survey data, emphasis should be given to statistical tools in the future so that their validity can be tested and the scope of the results broadened.

The relevance of quantitative flood risk analysis in urban areas is supported by results, indicating that $F-N$ and $F-D$ curves are a helpful and comprehensive tool to represent flood risk.

Results of both case studies show that the impact of nonstructural measures on flood risk can be addressed by the presented approach. Outcomes obtained by flood risk analyses provide new information to support emergency planning. Hence, results and conclusions of the flood risk analysis in Benaguasil are now being used to develop the Municipal Action Plan against Floods, which will include organization and communication schemes, content and planning of information campaigns, procedures in case of emergency, and recommendations for an improved flood risk management. In the Lodi case, results will support information campaigns and emergency management plans. 
Further work needs to be done to estimate the economic cost of the proposed non-structural measures and their efficiency. Flood risk analysis can support decision making by providing information to prioritize risk reduction measures. Thus, it is important to measure not only the impact but also the efficiency of different non-structural protection measures. Further research could be conducted to evaluate the efficiency of these measures by defining indicators, such as those found in the literature for dam safety management (ANCOLD, 2003).

In addition, it has to be remarked that equity is another fundamental principle from which alternatives can be prioritized and tolerability of risk guidelines are derived (ICOLD, 2005). It should be considered that there can be conflict in achieving equity and efficiency (Munger et al., 2009). Thus, the need for society to reduce flood risk cannot overcome the rights of individuals to protect themselves and their interests.

Regarding those tolerability risk guidelines, due to different characteristics of each investigation area, little research has been conducted to establish standards for flood risk assessment in urban areas. Several individual and societal criteria can be found in the literature (Vrijling, 2001), but tolerability guidelines on urban flood risk still need to be developed. Further investigation should therefore concentrate on the basis and development of a common standard to assess urban flood risk, but also include recommendations on how to adapt each particular case based on various aspects including location, public risk awareness, historical data, and impact of flood damages at regional/national/international scale, etc.

Acknowledgements. The work described in this paper was supported by the 2nd ERA-Net CRUE Funding Initiative, particularly funded by the Ministry of Science and Innovation of Spain and the Federal Ministry of Agriculture, Forestry, Environment and Water Management of Austria (Department 19B of the Government of Styria, Torrent and Avalanche control).

Authors would like to express their gratitude to the City Council of Benaguasil and the town of Lodi for their help and willingness to collaborate on this work.

Edited by: A. Thieken

Reviewed by: W. Lehman and three anonymous referees

\section{References}

AEMS: Commonwealth of Australia, Flood Warning, Manual 21, Australian Emergency Manuals Series, ISBN 978-1-921152-177, 2009.

Australian National Committee on Large Dams (ANCOLD): Incorporated Guidelines on Risk Assessment, October 2003.

Ayyub, B. M.: Elicitation of expert opinions for uncertainty and risks, CRC Press, 2001.
Baana, P. J. and Klijna, F.: Flood risk perception and implications for flood risk management in the Netherlands, Int. J. River Basin Manage., 2, 113-122, 2004.

Bowles, D. S.: ALARP Evaluation-Using Cost Effectiveness and Disproportionality to Justify Risk Reduction, Australian National Commission on Large Dams (ANCOLD) - Bulletin, 127, 89-106, August 2004.

Conselleria d'Obres Públiques, Urbanisme i Territori (COPUT): Plan de Acción Territorial de Carácter Sectorial sobre Prevención de Riesgo de Inundación en la Comunidad Valenciana (PATRICOVA), 2002 (in Spanish).

CRUE Research Funding Initiative: Synthesis Report No I-2009, Addressing the key findings of research, Risk Assessment and Risk Management: Effectiveness and Efficiency of Nonstructural Flood Risk Management Measures, Project Contract No: ERAC-CT-2004-515742, 2009.

Cunge, J. A., Holly, F. M., and Vervey, A.: Practical aspects of Computational River Hydraulics, Pitman Publ. Inc, London, 1990.

Dawson, W. R.: Generic depth-damage relationships for residential structures with basements, Economic Guidance Memorandum (EGM) 04-01, USACE, 2003.

DHS: Estimating Economic Consequences for Dam Failure Scenarios, Dams Sector, US Department of Homeland Security, September 2011, 2011a.

DHS: Estimating Loss of Life for Dam Failure Scenarios, Dams Sector, US Department of Homeland Security, September 2011, 2011b.

Douben, K. J.: Characteristics of river floods and flooding: a global overview, 1985-2003, Irrigation Drainage, 55, S9-S21, 2006.

EC: Directive 2007/60/EC of the European Parliament and of the Council of 23 October 2007 on the assessment and management of flood risks, 2007.

EC: Directive 2008/114/EC of the European Parliament and of the Council of 8 December 2008 on the identification and designation of European critical infrastructures and the assessment of the need to improve their protection, 2008.

Escuder-Bueno, I., Morales-Torres, A., and Perales-Momparler, S.: Urban Flood Risk Characterization as a tool for planning and managing. Workshop Alexandria, March 2010: Exploration of Tolerable Risk Guidelines for Levee Systems, Washington DC (USA), available at: www.ipresas.upv.es, www.sufri.tugraz.at, 2010.

Escuder-Bueno, I., Castillo-Rodríguez, J. T., Perales-Momparler, S., and Morales-Torres, A.: SUFRI methodology for pluvial and river flooding risk assessment in urban areas to inform decisionmaking, SUFRI project, WP3, final report, July 2011, available at: www.sufri.tugraz.at, 2011a.

Escuder-Bueno, I., Castillo-Rodríguez, J. T., Perales-Momparler, S., and Morales-Torres, A.: A complete and quantitative tool for flood risk analysis in urban areas: river and pluvial flooding, Proceedings UFRIM Conference, Graz (Austria), September 2011, 2011b.

Gómez, M. and Russo, B.: Criterios de riesgo asociados a escorrentía urbana, Jornadas de Ingeniería del Agua, 2009 (in Spanish).

Graham, W. J.: A procedure for estimating loss of life caused by dam failure, DSO-99-06, US Department of Interior, Bureau of Reclamation, 1999. 
Grossmann, G. and Seiser, T.: Final Report - Survey about risk awareness - SUFRI project, 2011 (unpublished report).

IEC/FDIS 31010, ISO International Standard: Risk management Risk assessment techniques, IEC/FDIS 31010:2009 (E), 2009.

International Commission on Large Dams (ICOLD): Risk Assessment in Dam Safety Management: A Reconnaissance of Benefits, Methods and Current Applications, Bulletin130, 2005.

Jöbstl, C., Zechner, S., Knoblauch, H., Pohl, R., Bornschein, A., Natale, L., Petaccia, G., Escuder-Bueno, I., Castillo-Rodríguez, J. T., Perales-Momparler, S., Morales-Torres, A., Bateman, A., Medina, V., Díaz, A., Grossmann, G., Kulmhofer, A., and Seiser, T.: SUFRI - Sustainable Strategies of Urban Flood Risk Management with non-structural measures to cope with the residual risk, Final Report, Graz 2011, available at: www.sufri.tugraz.at, 2011.

Jonkman, S. N.: Global Perspectives on Loss of Human Life Caused by Floods, Nat. Hazards, 34, 151-175, 2003.

Messner, F., Penning-Rowsell, E., Green, C., Meyer, V., Tunstall, S., and van der Veen, A.: FLOODSITE Evaluating flood damages: guidance and recommendations on principles and methods, Report T09-06-01, January 2007.

Munger, D. F., Bowles, D. S., Boyer, D. B., Davis, D. W., Margo, D. A., Moser, D. A., Regan, P. J., and Snorteland, N.: Interim tolerable risk guidelines for US Army Corps of Engineers dams. In USSD Workshop on the future of dam safety decision making: combining standards and risk, April 2009.

Nanía, L.: Métodos de transformación lluvía-escorrentía y de propagación de caudales, Hidrología superficial y subterránea, Universidad de Granada, 2002 (in Spanish).

Parker, D., Tunstall, S., and Wilson, T.: Socio-economic benefits of flood forecasting and warning, Flood Hazard Research Centre, Middlesex University, Queensway, Enfield, EN3 4SF, London, UK, 2005.

Penning-Rowsell, E., Floyd, D., Ramsbottom, P., and Surendran, S.: Estimating injury and loss of life in floods: A deterministic framework, Nat. Hazards, 36, 43-64, 2005.
Reiter, P.: RESCDAM - Loss of life caused by dam failure, the RESCDAM LOL method and its application to Kyrkosjarvi dam in Seinajoki, Water Consulting Ltd., 2001.

Roos, M.: Flood management practice in northern California, Irrigation Drainage, 55, 93-99, 2006.

Samuels, P., Klijn, F., and Dijkman J.: An analysis of the current practice of policies on river flood risk management in different countries, Irrigation Drainage, 55, 141-150, 2006.

Sayers, P. B., Hall, J. W., and Meadowcroft, I. C.: Towards riskbased flood hazard management in the UK, Proceedings of ICECivil Engineering 150 May 2002, 36-42, Paper 12803, 2002.

Scawthorn, C., Flores, P.; Blais, N., Seligson, H., Tate, E., Chang, S., Mifflin, E., Thomas, W., Murphy, J., Jones, C., and Lawrence, M.: HAZUS-MH flood loss estimation methodology, II: Damage and Loss Assessment, Nat. Hazards Rev., 7, 72-81, 2006.

Schanze, J., Hutter, G., Olfert, A., Penning-Rowsell, E.C., Parker, D., Harries, T., Werritty, A., Nachtnebel, H., Holzmann, H., Neuhold, C., Meyer, V., Kuhlicke, C., Schildt, A., Jessel, B., and Königer, P.: FLOOD-ERA Joint Report, CRUE Research Report No I-1: Systematisation, evaluation and context conditions of structural and non-structural measures for flood risk reduction, Project Contract No: ERAC-CT-2004-515742, 2008.

Serrano-Lombillo, A., Escuder-Bueno, I., de Membrillera-Ortuño, M. G., and Altarejos-García, L.: iPresas - Software for risk analysis, 23rd International Congress on Large Dams, Brasilia, 2009.

Simonovic, S. P.: Social criteria for evaluation of flood control measures - Winnipeg case study, Urban Water, 1, 167-175, 1999.

Témez, J. R.: Extended and Improved Rational method, Highways Administration of Spain, XXIV Congress Madrid Edition, 1991 (in Spanish).

US Bureau of Reclamation (USBR): Risk Based Profiling System, Technical Service Center, 2001.

Vrijling, J. K.: Probabilistic design of water defence systems in The Netherlands, Reliab. Eng. Syst. Safe., 74, 337-344, 2001.

Zechner, S., Jöbstl, C., and Knoblauch, H.: SUFRI Methodology for investigation of risk awareness of the population concerned, SUFRI project, WP4, final report, December 2011. 